Review

\title{
Mechanisms for localising calcineurin and CaMKII in dendritic spines
}

\author{
Christopher J. Penny, Matthew G. Gold* \\ Department of Neuroscience, Physiology \& Pharmacology, University College London, Gower Street, LONDON, WC1E 6BT, UK
}

\section{A R T I C L E I N F O}

\section{Keywords:}

Synaptic plasticity

Calcium

Calcineurin

CaMKII

Synapse

Spine

Anchoring protein

\begin{abstract}
A B S T R A C T
Calcineurin and calmodulin-dependent protein kinase II (CaMKII) are both highly abundant in neurons, and both are activated by calmodulin at similar $\mathrm{Ca}^{2+}$ concentrations in the test tube. However, they fulfill opposite functions in dendritic spines, with CaMKII activity driving long-term synaptic potentiation following large influxes of $\mathrm{Ca}^{2+}$ through NMDA-type glutamate receptors (NMDARs), and calcineurin responding to smaller influxes of $\mathrm{Ca}^{2+}$ through the same receptors to induce long-term depression. In this review, we explore the notion that precise dynamic localisation of the two enzymes at different sites within dendritic spines is fundamental to this behaviour. We describe the structural basis of calcineurin and CaMKII localisation by their interaction with proteins including AKAP79, densin-180, $\alpha$-actinin, and NMDARs. We then consider how interactions with these proteins likely position calcineurin and CaMKII at different distances from $\mathrm{Ca}^{2+}$ microdomains emanating from the mouths of NMDARs in order to drive the divergent responses. We also highlight shortcomings in our current understanding of synaptic localisation of these two important signalling enzymes.
\end{abstract}

\section{Introduction}

$\mathrm{Ca}^{2+}$ entry into dendritic spines is essential for triggering changes in both spine morphology and the strength of synaptic connections. $\mathrm{Ca}^{2+}$ signalling mechanisms have been most intensively researched in spines that lie postsynaptic to hippocampal CA3-CA1 synapses. These synapses are the leading model for understanding the molecular basis of synaptic plasticity, and their properties are thought to be characteristic of excitatory synapses in general. $\mathrm{Ca}^{2+}$ entry through NMDA-type glutamate receptors (NMDARs) in the postsynaptic membrane is the trigger for long-term changes in the strength of CA3-CA1 synapses [1], with the degree of $\mathrm{Ca}^{2+}$ influx determining the direction of plasticity [2]. Both low-frequency (e.g., $1 \mathrm{~Hz}$ ) homo-synaptic stimulation, and hetero-synaptic 'post' before 'pre' spike timing [3], trigger relatively small $\mathrm{Ca}^{2+}$ influxes into dendritic spines that induce long-term depression (LTD) [1]. Larger $\mathrm{Ca}^{2+}$ influxes that induce long-term potentiation (LTP) may be triggered by high-frequency homosynaptic stimulations (evenlyspaced or tetanic), and 'pre' before 'post' spike timing [3]. The molecular basis of $\mathrm{Ca}^{2+}$-driven synaptic plasticity has been intensively researched as the process is thought to underlie learning and memory. Two highly abundant $[4,5] \mathrm{Ca}^{2+} /$ Calmodulin (CaM)-sensitive enzymes have emerged as the key inducers of LTP and LTD of excitatory glutamatergic synapses following $\mathrm{Ca}^{2+}$ influx: the phosphatase calcineurin and CaM-dependent protein kinase II (CaMKII). The two enzymes control the phosphorylation state of synaptic proteins including AMPAtype glutamate receptors (AMPARs), thereby determining the conductance and numbers of these receptors in the postsynaptic density (PSD) [6]. This is an effective mechanism for altering synaptic strength, as AMPARs are the major mediator of fast excitatory synaptic transmission. Calcineurin dephosphorylation of AMPARs at residue Ser845, following smaller influxes of $\mathrm{Ca}^{2+}$, is an important component of LTD induction $[7,8]$. Larger influxes of $\mathrm{Ca}^{2+}$ activate $\mathrm{Ca}^{2+} / \mathrm{CaM}$-dependent protein kinase II (CaMKII) resulting in phosphorylation of proteins, including AMPARs at residue Ser831 to induce LTP [9-11]. Activated CaMKII is also thought to play a key structural role in LTP that supports enduring modifications in spine morphology [12]. Despite its status as the foremost mechanism for driving bidirectional synaptic plasticity [13], $\mathrm{Ca}^{2+}$ activation of calcineurin and CaMKII presents a paradox: how do enzymes that are activated with similar half-maximal $\mathrm{Ca}^{2+}$ and CaM concentrations in the test tube $[14,15]$ respond to different modes of $\mathrm{Ca}^{2+}$ influx through NMDARs in dendritic spines?

Elevations in second messengers including $\mathrm{Ca}^{2+}$ are localised within neurons [16]. Two-photon fluorescence lifetime imaging microscopy shows that CaMKII activation can be insulated within single spines [17]. Experiments with fast and slow $\mathrm{Ca}^{2+}$ chelators indicate that $\mathrm{Ca}^{2+}$ signalling may be further localised at the sub-spinal level $[18,19] . \mathrm{Ca}^{2+}$ 'microdomains' are known to occur in the vicinity of L-type $\mathrm{Ca}^{2+}$ channels, and enable spatial decoding of $\mathrm{Ca}^{2+}$ signals by these channels [20]. Highly localised $\mathrm{Ca}^{2+}$ signalling is emerging as an important feature of cellular signalling in further contexts, including coupling of $\mathrm{Ca}^{2+}$ release from acidic organelles and the endoplasmic reticulum [21]. It is likely that highly localised elevation of $\mathrm{Ca}^{2+}$ in the vicinity of

\footnotetext{
* Corresponding author.

E-mail address: m.gold@ucl.ac.uk (M.G. Gold).
} 
NMDARs is also important in dendritic spines. For example, localised activation of calcineurin in restricted $\mathrm{Ca}^{2+}$ microdomains could explain why only the phosphatase is activated during LTD. Such a model is consistent with the patterns of electrical sitmulation that induce LTP or LTD [1]. Investigation of localised cAMP signalling has revealed that cAMP cyclases, receptors, and phosphodiesterases are precisely coordinated within cAMP microdomains [22]. Protein-protein interactions involving anchoring proteins are fundamental to establishing this sub-cellular structure. In an analogous way, the internal structure of dendritic spines - in particular mechanisms for positioning CaMKII and calcineurin - will direct responses to localised $\mathrm{Ca}^{2+}$ signals. On this basis, the aim of this review is to consider how CaMKII and calcineurin are positioned in dendritic spines, and how this relates to their roles in responding to $\mathrm{Ca}^{2+}$ signals. We begin by discussing high-resolution structural information for calcineurin (Part 2) and CaMKII (Part 3), with a focus on describing sites on each enzyme that are known to mediate protein-protein interactions. After summarising the overall architecture of dendritic spines (Part 4), we consider how interaction sites on CaMKII and calcineurin are likely to determine the localisation of the enzymes in idealised 'naïve' spines (Part 5), and how this positioning may underlie their functions. Both calcineurin and CaMKII relocate in spines upon larger influxes of $\mathrm{Ca}^{2+}$ that drive LTP. In Part 6, we discuss the implications of this structural reorganisation.

\section{Calcineurin: structural overview \& key interaction sites}

Calcineurin is a heterodimer consisting of a catalytic subunit (A) of $\sim 60 \mathrm{kD}$ that presents a helix following the catalytic domain that interacts with a myristylated B subunit of $\sim 19 \mathrm{kD}$ [23] (Fig. 1a). Calcineurin is highly expressed throughout the brain, accounting for $1 \%$ of total brain protein in hippocampus [4], and it was first identified as a major neuronal CaM-binding protein ('calcineurin') prior to its subsequent characterisation as the $\mathrm{Ca}^{2+} / \mathrm{CaM}$-dependent phosphatase known as protein phosphatase 2B (PP2B) [24]. The B subunit resembles CaM with four EF hands that can each coordinate $\mathrm{Ca}^{2+}$. At resting cellular $\mathrm{Ca}^{2+}$ concentrations, high affinity sites 3 and 4 are fully $\mathrm{Ca}^{2+}$ occupied while sites 1 and 2 act as $\mathrm{Ca}^{2+}$ sensors. $\mathrm{Ca}^{2+}$ binding to sites 1 and 2 serves as a gateway for $\mathrm{Ca}^{2+} / \mathrm{CaM}$ binding, which releases an autoinhibitory element to bring about a further $\sim 10$-fold increase in phosphatase activity [15]. In vitro enzymatic assays suggest that calcineurin is activated with a half-maximal $\mathrm{Ca}^{2+}$ concentration in the range of a few hundred $\mathrm{nM}$ to a few $\mu \mathrm{M}$, depending on factors including CaM and $\mathrm{Mg}^{2+}$ concentration [25]. The half-maximal CaM concentration for activation in vitro is $\sim 15-30 \mathrm{nM}[26,27]$, much lower than the concentration of CaM present in dendritic spines with CaM accounting for $\sim 1.5 \%$ of total protein in hippocampus [28]. Two interaction sites have been identified on calcineurin that enable interaction with both substrates and anchoring proteins that present short linear motifs encoded by the amino acid sequence 'PxIxIT' and/or 'LxVP'.

\subsection{PxIxIT-type interactions}

The PxIxIT motif was first identified in the calcineurin substrate NFAT [29], which enters the nucleus following dephosphorylation to regulate transcription. NFAT dephosphorylation by calcineurin can be antagonised using a high affinity peptide with the consensus sequence PVIVIT with comparable efficacy to the calcineurin inhibitor cyclosporine [30]. PxIxIT motifs bind at a site equivalent to the RVxF site on protein phosphatase 1 (PP1) [31], with the PxIxIT sequence adopting a $\beta$-strand conformation (blue, Fig. 1b) that packs against and extends a

a

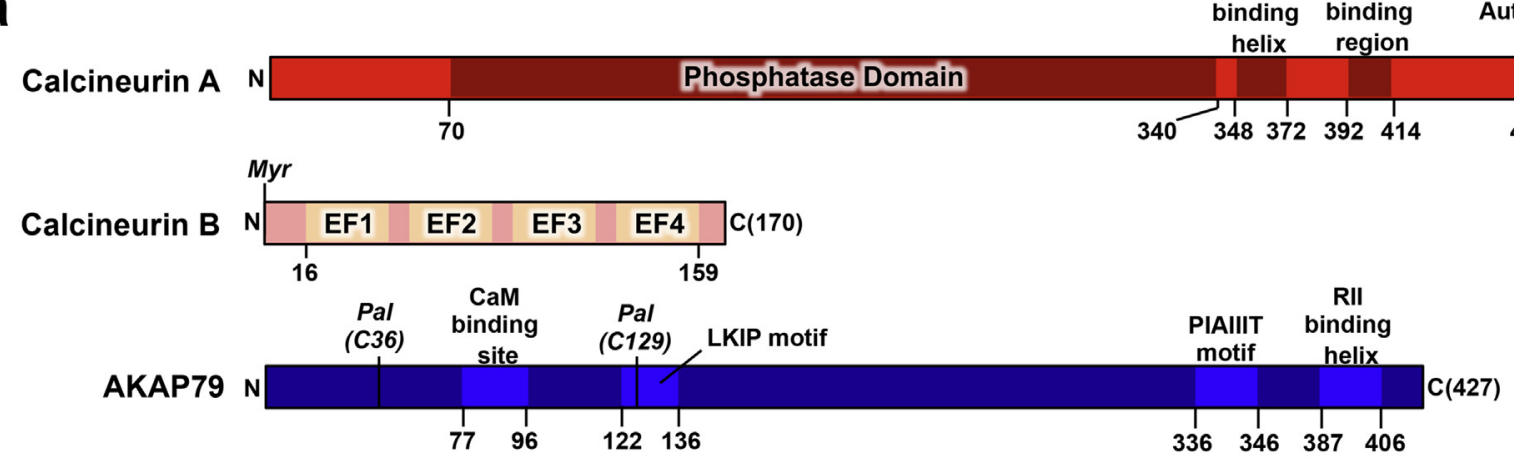
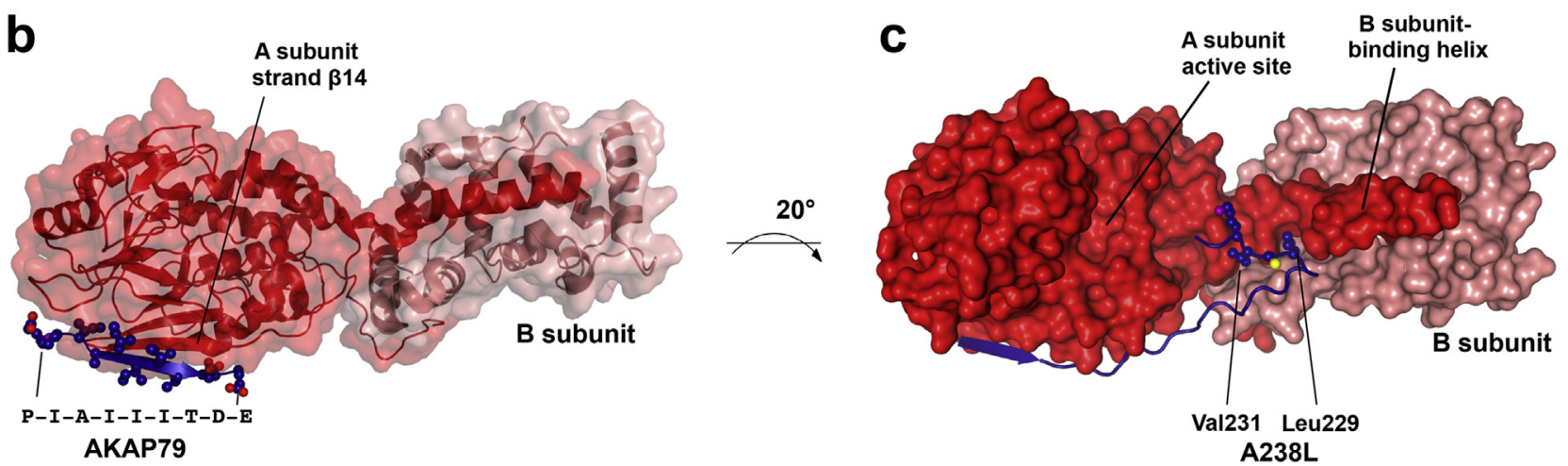

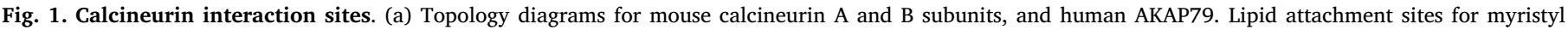

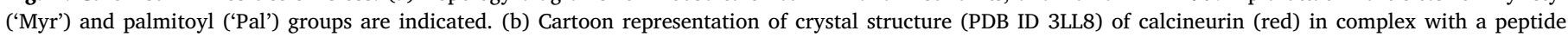

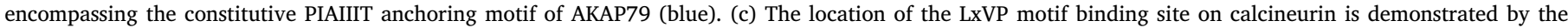

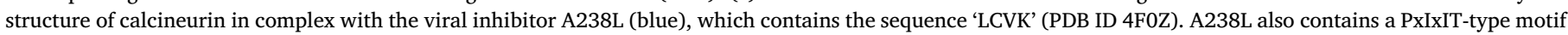

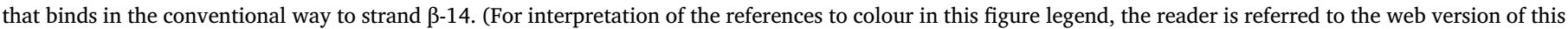
article.) 

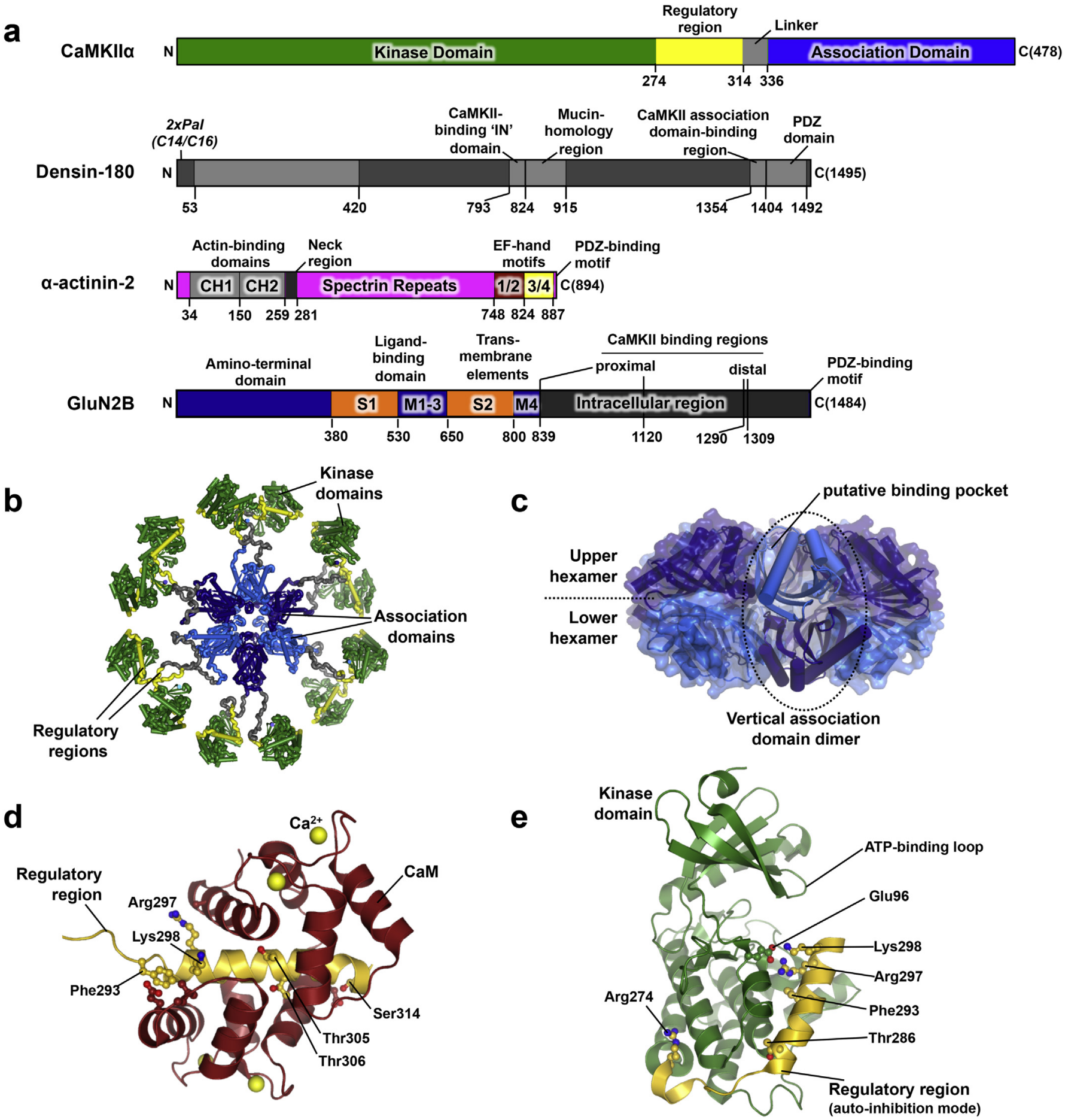

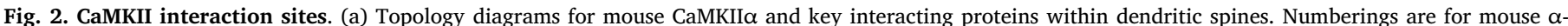

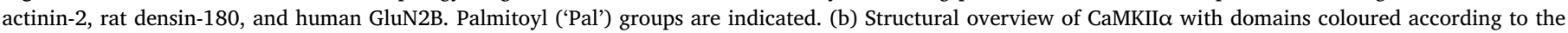

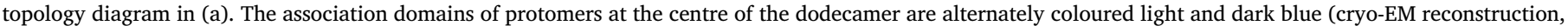

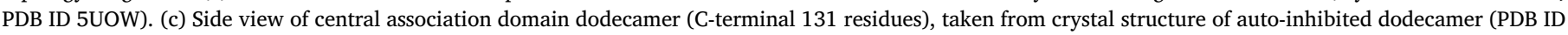

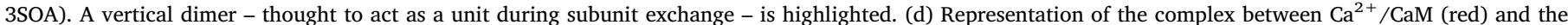

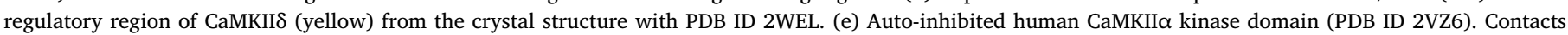

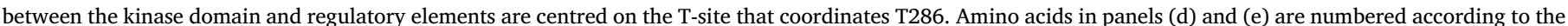

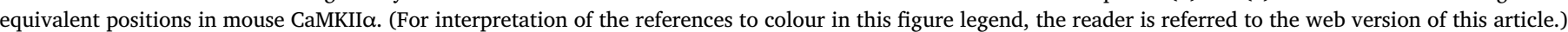

$\beta$-sheet on the calcineurin catalytic domain (red, Fig. 1b) [32]. The PxIxIT binding site is located on a different face to the phosphatase active site (Fig. 1c). Interactions between calcineurin and PxIxIT motifs are relatively low affinity in comparison to, for example, interactions between protein kinase A and its anchoring proteins [33,34]. Roy and colleagues showed that calcineurin binds to a range of PxIxIT motifs with affinities ranging from 15 to $250 \mu \mathrm{M}$ [35]. In dendritic spines, AKAP79 is the only protein besides NFAT known to interact with the PxIxIT binding site on calcineurin. AKAP79, which localises to the PSD [36], was first found to bind calcineurin using the yeast two-hybrid 
assay [37]. AKAP79 contains the sequence 'PIAIIITD' in its C-terminus [38] about 30 amino acids upstream of an anchoring helix for type II PKA regulatory subunits. Although this sequence is not a perfect match for the 'PxIxIT' consensus, the crystal structure of calcineurin in complex with a peptide spanning AKAP79 amino acids 336-346 confirms that the PIAIIITD sequence from AKAP79 forms a $\beta$ strand that interacts with strand $\beta-14$ in calcineurin, as predicted [39] (Fig. 1b). Hydrophobic side-chains project from either side of the $\beta$-strand formed by the AKAP79 PIAIIITD motif [39], unlike conventional PxIxIT motifs in which they only project on one side. This potentially enables calcineurin to bind to two copies of calcineurin at once. Consistent with this notion, crystallographic studies show that two copies of calcineurin can bind simultaneously to either side of $\beta$-strands formed by PVIVIT [32] and PIAIIITD [39] peptides. In addition, gas phase measurements [40] indicate that calcineurin can bind in a ratio of 2 calcineurin: 1 AKAP79. Conversely, interaction assays in solution [39,41], fluorescent imaging in cultured cells [39], and imaging by electron microscopy [41] support a binding ratio of 1 AKAP79: 1 calcineurin, with calcineurin binding to a single side of the PIAIIITD $\beta$-strand, as shown in Fig. 1b. Calcineurin interacts with the AKAP79 PIAIIITD motif in the low $\mu \mathrm{M}$ range $[39,41]$, consistent with high occupation of the site in dendritic spines given the high concentration of calcineurin in the brain [4].

\subsection{LxVP-type interactions}

A second short linear motif that interacts with calcineurin, 'YLAVP', was subsequently identified in the NFAT family [42,43]. Motifs of this class align with the consensus $\Phi \mathrm{LxVP}$ (where $\Phi$ is typically aromatic, and $\mathrm{x}$ cannot be glycine), and generally only interact with activated calcineurin [44]. A crystal structure of calcineurin in complex with the viral inhibitor protein A238L, which contains sequences conforming to both the PxIxIT and LxVP classes, shows how the LxVP-type motif of A238L binds at the interface of the calcineurin A and B subunits in proximity to the binding site for the immunosuppressant drug cyclosporine (Fig. 1c) [45]. The upstream PxIxIT-type motif of A238L interacts in the conventional mode with calcineurin strand $\beta-14$ (Fig. 1c). Calcineurin-interacting proteins may contain either or both of the two motif types, and there is no clear rule dictating spacing when both motifs are present [45]. AKAP79 is an example of a bipartite calcineurin-interacting protein [40], with the LxVP-type sequence 'LKIP' in its N-terminus mediating $\mathrm{Ca}^{2+} / \mathrm{CaM}$-dependent interactions with calcineurin [41]. Single particle analysis by electron microscopy shows that $\mathrm{Ca}^{2+} / \mathrm{CaM}$ triggers a contraction in the AKAP79-calcineurin complex brought about by association of the AKAP79 LKIP sequence [41] with activated calcineurin. The functional effects of removing LKIP from AKAP79 are subtle in comparison to removing the PIAIIITD calcineurin anchoring site [41]. AKAP79 is itself regulated by CaM binding to a novel '1-4-7-8' type CaM interaction motif centered $\sim 40$ amino acids N-terminal to the LKIP sequence [26] (Fig. 1a). Pull down assays show that CaM association with this site, at slightly higher $\mathrm{Ca}^{2+}$ concentrations than required to activate calcineurin, is required for engagement of the LKIP motif with calcineurin [26]. Bioinformatic analyses suggest that there may be many uncharacterised LxVP-type calcineurin motifs [46]. Commonly applied protein-protein interaction screening approaches, such as the yeast two-hybrid assay or MS identification of proteins in immuno-precipitates from brain extracts, are typically performed in the absence of elevated $\mathrm{Ca}^{2+}$. Therefore, there is scope for the identification of further proteins, in addition to NFAT and AKAP79, that employ LxVP-type interaction motifs in dendritic spines.

\section{CaMKII: structural overview \& key interaction sites}

CaMKII is a predominantly dodecameric enzyme, as indicated by its Stokes radius [47], imaging by electron microscopy using protein purified from native $[48,49]$ and transgenic $[50,51]$ sources, and protein crystallography [52]. The enzyme assembles into two stacked rings of six subunits with 622 symmetry [53] held together by C-terminal association domains (blue, Fig. 2a) that pack together in the interior of the ring (Fig. 2b). A minor subpopulation of 14 subunit multimers is also thought to exist [51,54]. Of the four CaMKII isoforms, $\alpha$ and $\beta$ are most highly expressed in the forebrain at a ratio of about three $\alpha$ per $\beta$ subunit, with CaMKII partitioning into a mixture of $\alpha / \beta$ heteromers (ratio $2 \alpha: 1 \beta$ ) and $\alpha$-only but not $\beta$-only homomers [55]. All four CaMKII isoforms are highly spliced, particularly within the variable region that falls between the regulatory elements (yellow, Fig. 2) and association domains (blue, Fig. 2) [56]. CaMKIIa adopts a disc-shaped structure with a maximum diameter of $\sim 25-30 \mathrm{~nm}$ (Fig. 2b) [50,51], whereas splice variants with shorter linker regions, such as $\beta 7$, are more compact [14]. The half-maximal CaM $\left(\mathrm{K}_{\mathrm{CaM}}\right)$ concentration for activation of CaMKII holoenzymes containing $\alpha$ and $\beta$ subunits is in the range of 22-68 nM [57], with higher CaM sensitivity for higher proportions of $\beta$ subunits [58]. Recent insights suggest that vertical CaMKII dimers (Fig. 2c) are the basic building block of holoenzymes [59], with activation triggering the inter-enzyme exchange of dimers over a time-scale of minutes [60] with a potential role for spiral-shaped (rather than discshaped) intermediates [54].

Unlike many protein kinases, CaMKII lacks a phosphorylation site in its activation loop. Instead, kinase activity is controlled by a key autophosphorylation site on residue T286 (residues are numbered by convention according to the mouse $\alpha$ isoform). Following CaMKII activation by $\mathrm{Ca}^{2+} / \mathrm{CaM}$ [61], intersubunit autophosphorylation may occur at T286 [62,63] to generate an autonomously active form of the enzyme [64-66], although this form is less active than $\mathrm{Ca}^{2+} / \mathrm{CaM}$ bound CaMKII [67]. Autonomously active CaMKII is likely important for the maintenance of LTP. Consistent with this notion, T286A substitution in mice occludes LTP and leads to learning deficits [10]. Generation of autonomous activity is linked to the frequency of $\mathrm{Ca}^{2+}$ oscillations [68]. The concentration of $\mathrm{Ca}^{2+}$ that triggers autonomy is shifted higher in the presence of high concentrations of PP1 [69], which may contribute to ensuring that CaMKII is only activated by large influxes of $\mathrm{Ca}^{2+}$. Withdrawal of $\mathrm{Ca}^{2+} / \mathrm{CaM}$ following establishment of autonomy leads to phosphorylation at two further threonine residues (positions 305 and 306), within the $\mathrm{Ca}^{2+} / \mathrm{CaM}$-binding region whose phosphorylation prevents subsequent $\mathrm{Ca}^{2+} / \mathrm{CaM}$ activation [70]. Mutation of these sites consequently affects synaptic plasticity and learning [71], for example, phospho-mimetic substitutions at positions 305 and 306 decrease CaMKII association with the PSD, occlude LTP and reduce learning [71]. In the following sections, we lay out mechanisms for localising CaMKII by association with the association domain (3.1), regulatory domain (3.2) or kinase domain (3.3).

\subsection{Association domains interactions}

The association domain of each CaMKII protomer within the holoenzyme folds into a wedge-like shape (Fig. $2 \mathrm{~b} \& \mathrm{c}$ ) with a prominent external $\mathrm{N}$-terminal helix that packs against a six-stranded $\beta$-sheet [72]. In each dimer spanning the upper and lower rings of the holoenzyme, the N-termini of the external helices face towards one another [51,52]. The association domains of CaMKII $\alpha$ assemble leaving a central hole of $\sim 20 \AA$ diameter [51,52], and with grooves lined by acidic residues presented on each vertical subunit interface. Interactions between the regulatory elements and these grooves underlie subunit exchange $[54,60]$. Densin- 180 is the only documented interaction partner for the CaMKII association domain [73,74]. Densin-180 is a core protein of the PSD [75] that does not span the cell membrane [76,77] but interacts with the internal face of the membrane through palmitoyl groups attached near to its N-terminus [78]. The efficacy of binding to the CaMKII association domain depends on the splice variant of densin-180 [73], with splicing altering the sequence of a critical binding region of $\sim 30$ amino acids within the C-terminal region of densin-180 [73] (Fig. 2a). The exact residues on the CaMKII association domain involved in coordinating densin-180 are unknown. Although densin-180 
can bind inactive CaMKII, approximately twice as much active CaMKII binds to a fusion of GST and the final $\sim 250$ amino acids of densin-180 (with CaMKII at $50 \mathrm{nM}$ ) [73]. According to a sedimentation assay, pT286-CaMKII binds to this GST-fusion with a $\mathrm{K}_{\mathrm{d}}$ of $\sim 200 \mathrm{nM}$ [73]. Small-angle x-ray scattering shows that CaMKII activation increases the holoenzyme radius of gyration, consistent with release of kinase domains from centrally docked positions, adjacent to the hub domain [59]. Therefore, it is likely that the interaction involves the vertical outward-facing surfaces of the association domains, at least in part. Each protomeric association domain also contains a deep cavity formed by residues within its C-terminus (Fig. 2c), but no ligands have been identified to date for this putative binding pocket [72,79].

\subsection{Regulatory domain interactions}

The regulatory region of CaMKII (typically denoted as spanning residues 274-314 in mouse CaMKII $\alpha$ ) performs a dual role in controlling the activity and localisation of the kinase [14]. $\mathrm{Ca}^{2+} / \mathrm{CaM}$ (red, Fig. 2d) wraps around a helix formed by amino acids 293-314 (yellow, Fig. 2d) to release autoinhibitory elements of the regulatory region [80] from the kinase domain to allow ATP binding, permit substrate phosphorylation $[61,79]$, and expose T286 for trans-phosphorylation. $\mathrm{Ca}^{2+}$ / CaM binding also frees amino acids 274-291 to engage in inter-subunit interactions that enable cooperative activation [81]. Isothermal measurements reveal that CaM must overcome an energy barrier for release of the binding elements within CaMKII from the kinase domain [79]. Autophosphorylation at T286 traps CaM, decreasing the off rate by 1000-fold [82], whereas T305/306 phosphorylation occludes CaM binding $[83,84]$. The regulatory domain mediates two important protein-protein interactions besides CaM. First, CaMKII $\beta$ binds directly to F-actin [85] using elements in exon V1 that is not spliced into the regulatory region of CaMKII $\alpha$ [86], although mixed $\alpha / \beta$ holoenzymes also associate with F-actin [85]. F-actin binding does not activate CaMKII $\beta$ [87]. The interface is disrupted by $\mathrm{Ca}^{2+} / \mathrm{CaM}$ [88], which provides a mechanism to couple $\mathrm{Ca}^{2+}$ influx to CaMKII release from the actin cytoskeleton. This interaction enables CaMKII $\beta$ to bundle F-actin in vitro [87] and, consistent with a key role for the $\beta$ isoform in regulating the cytoskeleton, CaMKII $\beta$ knock-down alters neurite extension and synapse formation [87,89]. Second, the regulatory domain of CaMKII $\alpha$ interacts with the actin crosslinking protein $\alpha$-actinin [74]. In mammals, there are four $\alpha$-actinin isoforms with distinct expression patterns, including in the developing [90] and adult [91] brain. $\alpha$-actinin-2 is localised to dendritic spines of glutamatergic neurons, where its expression increases postnatally [90,92]. Following its spectrin-like repeats, $\alpha$-actinin- 2 contains four EF hand motifs with homology to CaM (Fig. 2a). EF hands 3 and 4 of $\alpha$-actinin- 2 are thought to associate with the CaMKII $\alpha$ regulatory region with no requirement for $\mathrm{Ca}^{2+}$ [93]. Consistent with this model, the interaction is sensitive to the phosphorylation state of T305 [94], and $\alpha$-actinin competes with $\mathrm{Ca}^{2+} / \mathrm{CaM}$ for binding to CaMKII [94]. Unlike CaM, $\alpha$-actinin binding is not affected by CaMKII T306 phosphorylation [94]. $\alpha$-actinin only weakly activates CaMKII [93], presumably because the absence of interactions with EF hands 1 and 2 does not release the autoinhibitory elements of CaMKII in the same way as CaM. This suggests that $\alpha$-actinin's primary role is not to activate CaMKII and may instead be structural.

\subsection{Kinase domain interactions}

The autoinhibited kinase domains of all four human CaMKII isoforms adopt highly similar conformations [79]. For all isoforms, in the absence of $\mathrm{T} 286$ phosphorylation or $\mathrm{Ca}^{2+} / \mathrm{CaM}$ binding, the regulatory elements (yellow, Fig. 2e) dock at two adjacent regions within the kinase domain (green, Fig. 2e). In human $\alpha$ and $\beta$ CaMKII isoforms, contacts are primarily through the ' $\mathrm{T}$ ' site (centred on the binding pocket for T286) rather than the ' $\mathrm{S}$ ' (substrate binding) site [79] (Fig. 2e). E96 is oriented away from the ATP binding pocket in the autoinhibited kinase (Fig. 2e), which prevents binding of ATP [79]. In activated CaMKII, both $\mathrm{S}$ and $\mathrm{T}$ sites are available for interaction with substrates and interaction partners. GluN2B (formerly 'NR2B') subunits of NMDARs have emerged as the key interaction partner for activated CaMKII. NMDARs are tetrameric receptors composed of an obligatory NR1 dimer and differing type II subunits [95]. GluN2B [96-99] and, to a lesser extent, GluN2A [100] subunits bind to all activated CaMKII isoforms [101]. CaMKII binds with comparable affinity to two separate sites within the GluN2B C-terminal tail: a distal site between residues 1290-1309 [102] that encompasses a CaMKII phosphorylation site at S1303 [103]; and a less clearly defined proximal site within the region 839-1120 that does not undergo CaMKII phosphorylation $[101,104,105]$. S1303 phosphorylation drives the dissociation of autophosphorylated CaMKII from GluN2B peptides corresponding to the distal site [102]. Consistent with phosphorylation weakening the affinity of the interaction, the substitution S1303D in GluN2B impairs LTP [106]. Since T286-autophosphorylated CaMKII binds to GluN2A subunits with a reduced affinity compared to GluN2B [99], altering the ratio of GluN2A:GluN2B through brain development is thought to be a mechanism for altering synaptic propensity for LTP [106]. A two amino acid insertion in the distal binding site of GluN2A underlies the different affinities of GluN2A and B for CaMKII [107].

Disruption experiments with peptides that occupy either the $\mathrm{S}$ or $\mathrm{S}$ and $\mathrm{T}$ sites on CaMKII show that interaction with GluN2B involves occupation of the T-site [94,99,102,108]. In comparison, sequence surrounding the important regulatory residue S831 in GluA1 subunits does not associate with the $\mathrm{T}$ site, so long-term interactions between CaMKII and AMPARs do not occur. Higher peptide concentrations are required to disrupt the GluN2B-CaMKII interaction in situ than to inhibit CaMKII activity [109], suggesting that the interaction is very robust in the context of the PSD. Experiments with CaMKII variants bearing S or $\mathrm{T}$ site mutations suggest that residues prior to S1303 in NMDARs initially bind to the S-site before the autoinhibitory domain of CaMKII vacates the T-site enabling its occupation by GluN2B [108]. C. elegans CaMKII kinase domain crystal structures showing binding to adjacent regulatory segments (PDB ID 3KK8) [81], and association with the 18mer peptide inhibitor CaMKIINtide (PDB ID 3KL8) [81], provide insights into possible binding modes for substrates such as NMDARs that occupy the $\mathrm{T}$ site. In addition to elements that interact with the association domain of CaMKII, densin-180 contains a sequence known as the 'IN' domain immediately $\mathrm{N}$-terminal to its mucin-like domain (Fig. 2a, residues 793-824). This sequence also associates with CaMKII kinase domains, contingent on activation [97]. The $K_{d}$ for interaction between CaMKII and this region of densin-180 is decreased by more than 100 -fold by CaMKII activation to $\sim 75-100 \mathrm{nM}$ [74]. The inhibitor 'N-tide' potently inhibits this interaction consistent with occupation of the T-site by densin-180. Mutational analysis shows that the binding mode for the densin-180 'IN' domain is subtly different to GluN2B [97]. Interaction with the densin-180 IN domain selectively inhibits CaMKII phosphorylation of substrates that occupy the T-site. In summary, protein-protein interaction sites have been identified in each CaMKII sub-domain. This imbues CaMKII dodecamers with the potential to engage in highly complex patterns of interaction.

\section{Overview of dendritic spine ultrastructure}

Before considering how calcineurin and CaMKII are positioned within dendritic spines, it is important to highlight relevant features of dendritic spine ultrastructure [110]. The most commonly studied dendritic spines are postsynaptic to excitatory hippocampal CA3-CA1 synapses. These spines are supported by a complex cytoskeletal ultrastructure based upon actin filaments [111]. Analysis of synaptic ultrastructure has focused on prominent mushroom-shaped spines [112]. Electron microscope (EM) tomography shows that mushroom spines are supported by a network of thin F-actin filaments that are typically shorter than $100 \mathrm{~nm}$ [111]. F-actin branching is most dense at 
the edges of the PSD, and lateral to the PSD [111,113]. The cytosplasmic face of the PSD connects to actin filaments [111]. The PSD itself is disc-shaped, with a core depth of $\sim 30 \mathrm{~nm}$, and a diameter of $\sim 180-350 \mathrm{~nm}$, depending on the number of AMPARs that are incorporated [114]. The number of NMDARs per PSD is not correlated with PSD width, whereas larger PSDs contain proportionately more AMPARs [114]. AMPAR endocytosis occurs in part within an 'endocytic zone' in the membrane immediately surrounding the PSD [6].

The core structure of the PSD comprises a lattice of vertical filaments, including membrane-associated guanylate kinase (MAGUK) proteins PSD-95 and SAP-97, linked to horizontal filaments such as SHANK $[115,116]$ by scaffold proteins including GKAP [110]. The vertical filaments are typically spaced $\sim 14 \mathrm{~nm}$ from one another [117]. In an average forebrain synapse, there are $\sim 300$ copies of PSD-95, 150 SHANK family proteins, and 150 GKAPs $[110,118]$. The composition of the average PSD changes markedly over development, which makes it challenging to establish general molecular mechanisms for synaptic plasticity [119]. For example, whereas the number of GluN2A subunits in the average PSD increases with age, the reverse is true of GluN2B subunits [119]. PSD proteins exhibit a laminar organisation according to immunogold-EM labeling, with PSD-95 sharing an axiodendritic plane with the NMDAR C-terminus in an electron-dense layer close to the postsynaptic membrane (Fig. 3a), and SHANK and GKAP positioned on the cytoplasmic face of the PSD, $\sim 30 \mathrm{~nm}$ inside the membrane [120]. This deeper layer, which contains horizontal filaments including SHANK and homer and extends to about $50 \mathrm{~nm}$ inside the membrane, is known as the 'pallium' $[120,121]$. PDZ domain interactions play a key role in supporting the structure of the PSD. For example, the second PDZ domain of PSD-95 binds to the C-terminus of NMDARs [122]. Consistent with a key structural role for PSD-95, reducing expression of this MAGUK protein leads to breakdown of the molecular organisation of the PSD [117]. Immunogold labeling studies show that PSD-95 forms $17 \mathrm{~nm}$ filaments that run from $\mathrm{N}$ to $\mathrm{C}$ along the axiodendritic axis with the N-terminal PDZ domains engaging ion channels including NMDARs closer to the membrane, and the C-terminal SH3 and guanylate kinase (GK) domains engaging other proteins more distally [117] (Fig. 3a).

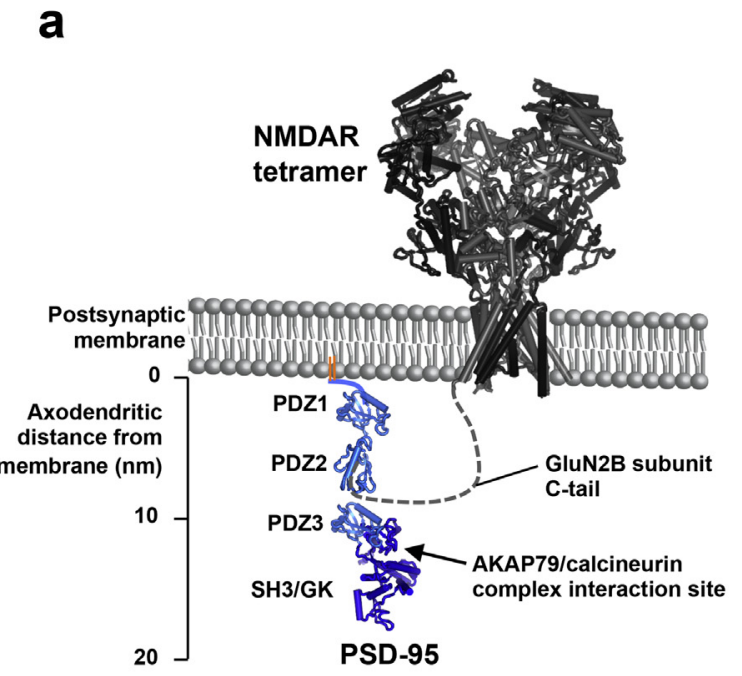

It is not straightforward to assign positions for CaMKII and calcineurin within the dendritic ultrastructure, since the localisation of both enzymes is altered by $\mathrm{Ca}^{2+}$ influx. To account for this complication, we will first consider dynamic postsynaptic positioning of CaMKII and calcineurin in two idealised cases: in non-stimulated ('naïve') synapses (section 5) and during large influxes of $\mathrm{Ca}^{2+}$ that trigger LTP (section 6).

5. Calcineurin and CaMKII positioning in dendritic spines engaged in naïve synapses

\subsection{Positioning of calcineurin}

The key postsynaptic anchoring site for calcineurin is the constitutive PIAIIITD anchoring motif presented within the C-terminus of AKAP79. AKAP79 is consistently identified in PSD extracts by immunoblotting [36], and quantitative mass spectrometry (MS) supports an approximate abundance of 20 copies of AKAP79 per PSD [118]. EM imaging of immunogold labelled AKAP79 in the dendrites of CA1 pyramidal cells reveals strong dendritic labeling of AKAP79 as expected, but suggests that AKAP79 is also present on membranes in the endocytic zone [123]. Consistent with this, subsequent studies have reported that a pool of AKAP79 resides on endosomes [124]. AKAP79 directly interacts with the C-terminal SH3 and guanylate kinase domains of the vertical filament proteins PSD-95 and SAP-97 through central binding elements [125]. This interaction provides a reference point to position AKAP79 within the PSD. The SH3 and GK domains of PSD-95 are located in a laminar plane $\sim 15 \mathrm{~nm}$ from the postsynaptic membrane (Fig. 3a). The second PDZ domain of PSD-95 also directly interacts with the C-termini of NMDARs subunits [122]. This pattern of interactions is consistent with AKAP79 presenting an anchoring site for calcineurin close to NMDARs.

AKAP79 also binds directly to membrane phospholipids and a number of integral membrane proteins, consistent with it positioning calcineurin very close to the postsynaptic membrane. For example, the anchoring protein directly interacts with L-type $\mathrm{Ca}^{2+}$ channels [126]

b
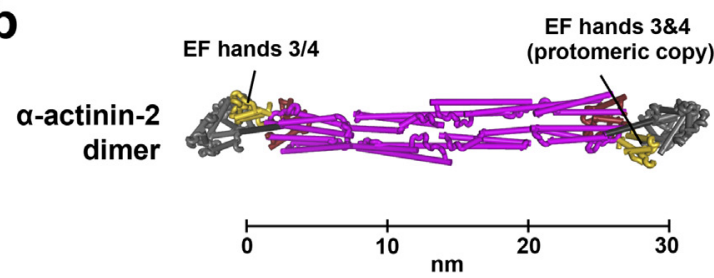

CaMKIla dodecamer

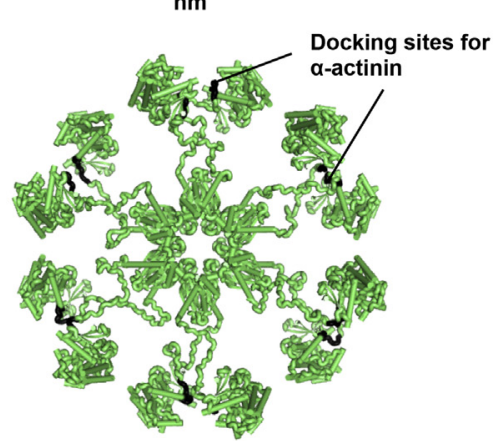

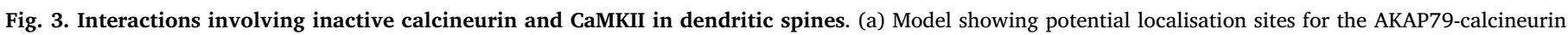

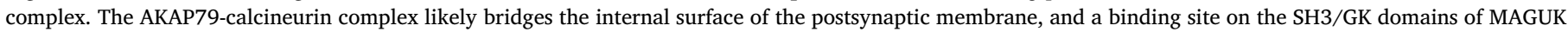

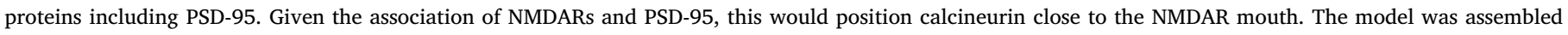

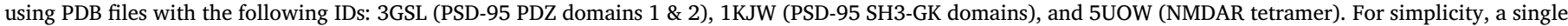

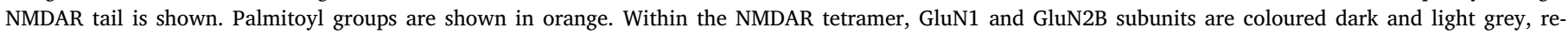

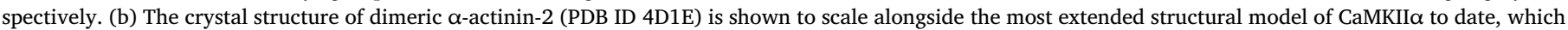

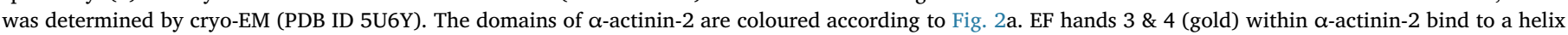

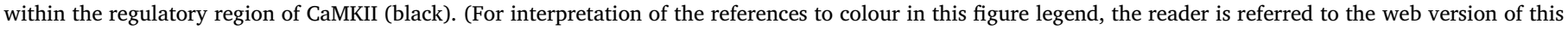
article.) 
and certain adenylyl cyclase isoforms [127]. AKAP79 contains three basic regions within its first 150 amino acids that associate with acidic phospholipids [128] and F-actin [129], and it is also palmitoylated at cysteines 36 and 129 [130,131]. Low-resolution models of the AKAP79calcineurin complex from negative-stain EM show that AKAP79 assumes an extended conformation [41] that could enable simultaneous interaction with both the postsynaptic membrane and MAGUK Cterminal domains. Lipid and protein interactions involving AKAP79 point towards the existence of an anchoring site that would support calcineurin activation within $\mathrm{Ca}^{2+}$ microdomains centered on NMDARs following small influxes of $\mathrm{Ca}^{2+}$ that trigger LTD (Fig. 3a). This model is supported by investigations of the functional effects of removing the PIAIIITD anchoring site of the rat ortholog AKAP150: in geneticallymodified mice, LTD can no longer be induced at CA3-CA1 synapses if either the PIAIIITD site is removed [132], or if AKAP150 is knocked out altogether [133,134]. In sum, studies of AKAP79/150 interactions, localisation and function indicate that this anchoring protein is critical for positioning calcineurin during the induction of LTD.

\subsection{Positioning of CaMKII}

Quantitation of the abundance of proteins in purified PSDs by gel electrophoresis shows that the average PSD contains $\sim 80$ CaMKII holoenzymes [135], corresponding to $\sim 6 \%$ of total PSD mass, although a recent MS analysis reported a higher copy number [136]. In dendritic spines of CA1 stratum radiatum, CaMKII immunogold labeling density peaks about $40 \mathrm{~nm}$ inside the postsynaptic membrane, within the pallial layer [137]. Electron tomography of isolated PSDs supports the notion that most CaMKII associated with the PSD is positioned at a greater depth from the postsynaptic membrane than core proteins such as PSD95 [138]. Within $25 \mathrm{~nm}$ of postsynaptic membranes in CA1 stratum radiatum, CaMKII labeling is concentrated to the lateral edges of the PSD [137]. This suggests that CaMKII can attach to PSDs in two ways: at sites within the pallial layer, and within the core but at the edges of the PSD. Since these studies were performed with PSDs extracted from brain - therefore deriving in some cases from synapses that have undergone LTP - it is not clear to what extent these two locations represent CaMKII anchoring locations in naïve synapses. Inactive CaMKII can bind $\alpha$-actinin, actin, and - to some extent - densin-180 (Section 3). In this section, we consider how interaction with these proteins is likely to determine CaMKII localisation prior to influx of $\mathrm{Ca}^{2+}$.

$\alpha$-actinin forms an antiparallel dimer via central inflexible spectrinlike repeats to create a rigid rod with a double-headed actin binding capability [139] (Fig. 3b). The dimeric elongated conformation of $\alpha$ actinin enables it to effectively crosslink actin filaments, and to tether Factin to a range of intracellular targets. Its best-characterised role is at the sarcomeric $Z$-disk in striated muscle where it links F-actin and titin [140]. The ability of $\alpha$-actinin to cross-link actin with diverse proteins is also utilised in other settings, such as in the assembly of focal adhesions in the leading protrusions of migrating cells [141], and in cytokinesis [142,143]. Knock-down or overexpression of $\alpha$-actinin-2 in rat hippocampal neurons leads to striking defects in spine formation, consistent with an additional role for the protein in regulating dendritic actin dynamics [144]. $\alpha$-actinin is sensitive to regulation by the plasma membrane phospholipid $\mathrm{PI}(4,5) \mathrm{P}_{2}$ [145] by an interaction with residues in the actin binding domain [146,147], which may underlie $\alpha$ actinin's ability to regulate membrane dynamics. $\alpha$-actinin- 2 is highly localised to dendritic spines [90,144], and sub-synaptic immunogold labeling shows that it resides within the PSD but not at a single laminar depth. $\alpha$-actinin-2 labeling is also observed on actin filaments in the spine neck [92]. $\alpha$-actinin isoforms exhibit variable regional expression, with relatively low expression in CA1 dendrites [92].

The two copies of EF hands $3 \& 4$ in the $\alpha$-actinin- 2 dimer are separated by $\sim 28 \mathrm{~nm}$ (yellow, Fig. 3b) [148], whereas the maximum separation of $\alpha$-actinin-binding motifs in the CaMKII dodecamer is only $\sim 22 \mathrm{~nm}$ (black, Fig. 3b) according to the most extended structural conformations proposed for the CaMKII holoenzyme [51]. Therefore, it appears unlikely that $\alpha$-actinin operates by bridging two regulatory domains within a single CaMKII holoenzyme. For mixed $\alpha / \beta$ CaMKII holoenzymes, the ability of $\beta$ subunits to bind directly to F-actin likely enables formation of ternary complexes between $\alpha$-actinin, actin, and mixed CaMKII holoenzymes. In general, actin and $\alpha$-actinin naturally organise into arrays with regular spacing [149], supported by proteins such as titin that bridge between them [140]. However, there is little evidence for the formation of actin lattices in dendritic spines [111]. $\alpha$ actinin may also potentially stabilise CaMKII association with NMDARs [150], and densin-180 [74]. Overall, it is difficult to assign a precise localisation site for CaMKII anchored to $\alpha$-actinin, as $\alpha$-actinin engages in many additional interactions with no single sub-spinal locus.

Inactive CaMKII associates to some extent with densin-180 in vitro via the association domain, although the affinity of the interaction is increased by activation of the kinase [74]. Densin-180 is highly localised to spines, and it is enriched in PSD extracts [75]. Its ability to interact with elements of the horizontal filament protein SHANK, including the SH3 domain [151], indicates that at least part of densin-180 is located in the pallium of the PSD. Densin-180 contains a C-terminal PDZ domain that binds to a PDZ recognition motif [152] formed by the last $\sim 6$ amino acids of $\alpha$-actinin [74]. Experiments with purified protein [96] show that ternary complex formation between CaMKII, densin-180 and $\alpha$-actinin is possible, and densin- 180 stabilises interaction between CaMKII and $\alpha$-actinin [96]. This interaction mode may enable association of some CaMKII in the PSD pallium prior to LTP induction. Studies with densin-180 knock-out mice support the idea that the anchoring protein is involved in positioning CaMKII in dendritic spines [153]. Mice lacking densin-180 exhibit deficits in objectplace recognition, and suffer from increased anxiety as measured by open field behavior [153]. Consistent with ternary densin-180/ $\alpha$-actinin/CaMKII complex formation in vivo, $\alpha$-actinin levels in densin-180 knockout mice are reduced by one third in both total brain and fractionated PSDs. Intriguingly, resting levels of pT286-CaMKII - but not total CaMKII - are reduced in PSDs of mice lacking densin-180. Therefore, densin-180 may be more important for supporting tethering of activated CaMKII at the PSD [153].

\section{Changes in sub-spinal location during large influxes of $\mathrm{Ca}^{2+}$}

Calcineurin anchoring by AKAP79 enables the phosphatase to sense the small, localised influxes of $\mathrm{Ca}^{2+}$ through NMDARs that induce LTD [133]. Our current understanding of the molecular architecture of the AKAP79 signalling complex suggests that AKAP79 initially positions the $\mathrm{Ca}^{2+} /$ CaM-sensitive elements of calcineurin within $\mathrm{Ca}^{2+}$ microdomains emanating from the mouths of NMDAR receptors (Fig. 3a). No equivalent anchoring site for CaMKII has been identified in naïve synapses. In spite of their similar inherent sensitivities to $\mathrm{Ca}^{2+}$, this differential initial localization of calcineurin and CaMKII may partly explain why only calcineurin responds to small influxes of $\mathrm{Ca}^{2+}$ that induce LTD. However, both enzymes relocate following strong activation of NMDARs governed by changes in molecular interactions that are regulated by $\mathrm{Ca}^{2+} / \mathrm{CaM}$ (Fig. 4a). In this section, we will consider how $\mathrm{Ca}^{2+} /$ CaM-induced changes in sub-spinal location may support longlasting activation of CaMKII, and explain why calcineurin does not dephosphorylate AMPARs during induction of LTP.

\subsection{Calcineurin dynamics}

Binding of $\mathrm{Ca}^{2+} / \mathrm{CaM}$ to a helix spanning position 79-86 in AKAP79 [26] leads to dissociation of the anchoring protein from in vitro membrane preparations containing the acidic phophoslipid PI(4,5) $\mathrm{P}_{2}$ [128]. In a physiological context, strong NMDAR association triggers removal of rat AKAP150 from dendritic spines [129,132]. Dissociation from Factin may also contribute to $\mathrm{Ca}^{2+} / \mathrm{CaM}$-triggered re-localisation of AKAP79 [129]. In this way, $\mathrm{Ca}^{2+}$ influxes can be expected to remove a 
a

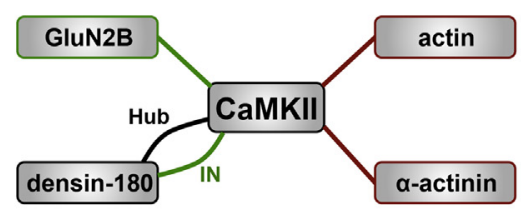

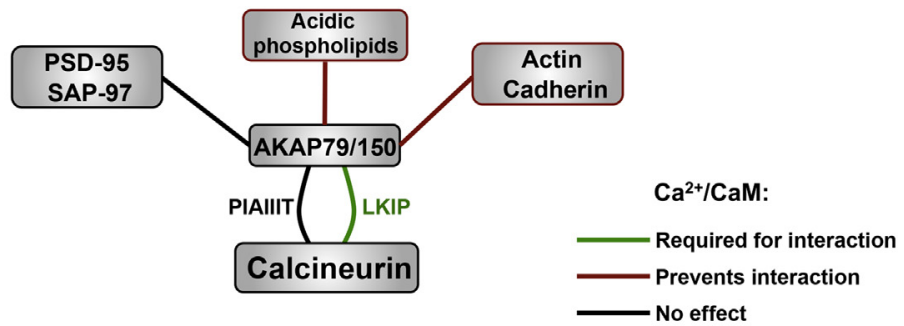

b

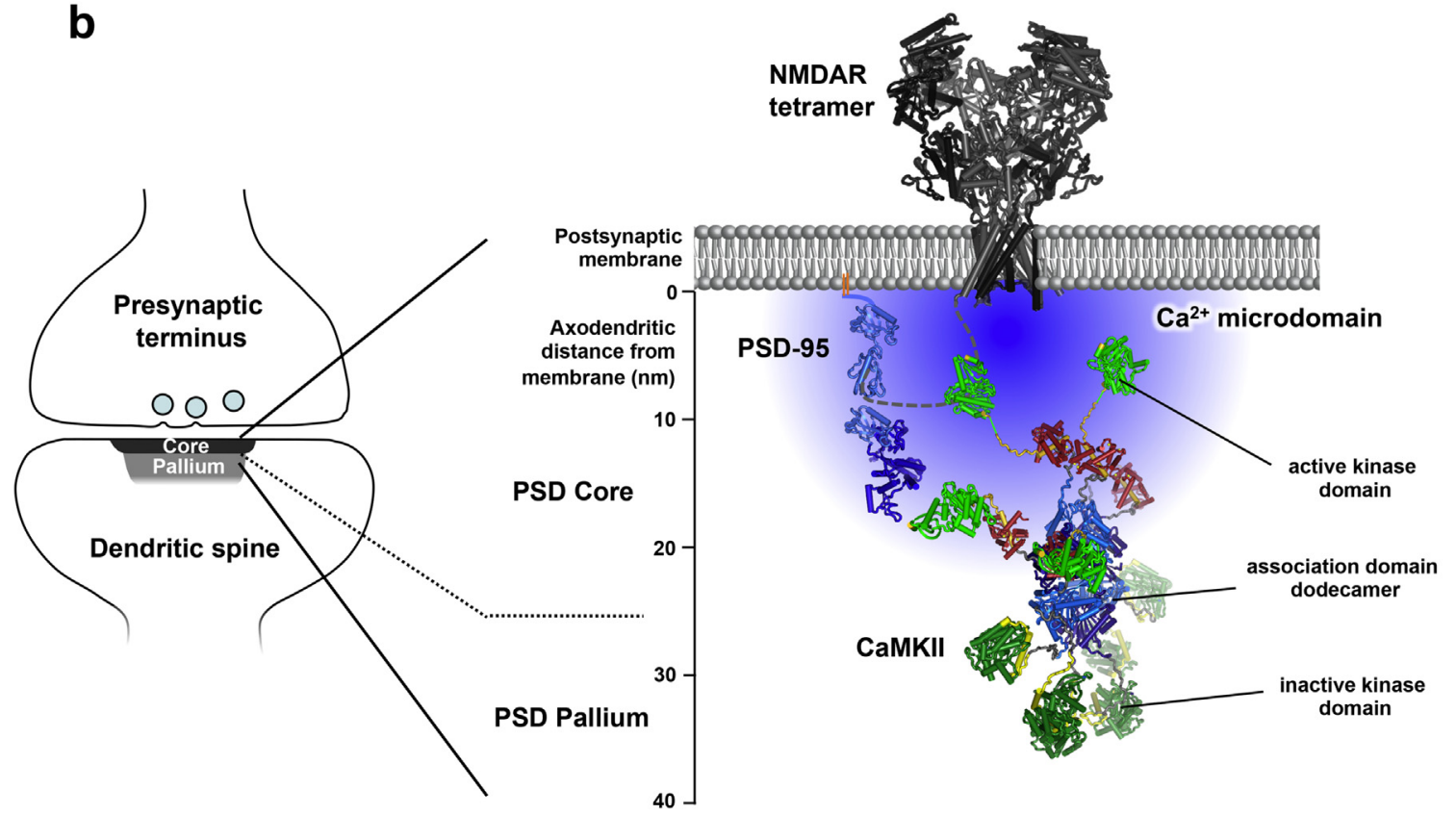

Fig. 4. Coordination of active CaMKII in the PSD. (a) Network diagram summarising molecular interactions involving calcineurin and CaMKII that are important for positioning the enzymes in dendritic spines. Links are coloured according to how they are affected by $\mathrm{Ca}^{2+} / \mathrm{CaM}^{2}$. The interaction between the CaMKII association and densin-180 is labelled 'Hub'; the interaction between CaMKII and the densin-180 IN domain is labelled 'IN'. (b) Structural model showing anchoring of active CaMKII within the PSD. The nearest neighbour distances of receptors and vertical filaments in the PSD is consistent with CaMKII associating 'side-on' with the PSD. This may enable the kinase to bridge localisation sites within the PSD core, including interactions sites within the tails of NMDAR subunits, and the PSD pallium. Interaction partners within the PSD pallium may include densin-180 and $\alpha$-actinin (not shown). CaMKII is modelled using structures of the autoinhibited dodecamer (PDB ID 5UOW), and the complex of CaMKII $(11-335)$ and $\mathrm{Ca}^{2+} / \mathrm{CaM}$ (PDB ID 2WEL). One implication of side-on CaMKII insertion is that CaMKII protomers within the same holoenzymes will have different access to localised $\mathrm{Ca}^{2+}$ microdomains (blue) emanating from the mouths of NMDARs. This may enable simultaneous interactions between active and inactive protomers within single CaMKII dodecamers. (For interpretation of the references to colour in this figure legend, the reader is referred to the web version of this article.)

major anchoring site for calcineurin in the vicinity of its substrates within the PSD. This may provide a mechanism for preventing dephosphorylation of Ser845 on GluA1 receptors during LTP. However, this raises a question of why $\mathrm{Ca}^{2+} / \mathrm{CaM}$-triggered release of AKAP79 from the PSD doesn't prevent AMPAR dephosphorylation by calcineurin during LTD. In vitro binding assays show that CaM associates with calcineurin at lower half-maximal $\mathrm{Ca}^{2+}$ concentrations than it does with AKAP79 [26]. Therefore, the window of $\mathrm{Ca}^{2+}$ concentrations within which LTD occurs may potentially trigger calcineurin dephosphorylation without dissociating the AKAP from PSDs. Finally, association of calcineurin with LxVP-type interactions motifs, dependent on $\mathrm{Ca}^{2+} / \mathrm{CaM}$, is an emerging calcineurin anchoring mechanism. However, besides AKAP79 [40,41], there are no reports of LxVP-type interactions within dendritic spines. This may be because interactions of this type are harder to detect than those that occur in the absence of elevated $\mathrm{Ca}^{2+}$.

\subsection{CaMKII dynamics}

CaMKII distributes evenly in naïve dendrites [154,155]. Upon neuronal activation, the kinase assumes a punctate distribution and localises with PSD proteins unless NMDAR antagonists are present $[108,154,155]$. The speed of recruitment depends on the ratio of $\alpha$ to $\beta$ subunits, with CaMKII $\alpha / \beta$ heteromers accumulating at the PSD more slowly than CaMKII $\alpha$ homomers [154] presumably due to direct interactions between $\beta$ subunits and actin [85]. Approximately one fifth of CaMKII that localises at the PSD during LTP induction remains associated indefinitely, long after the triggering $\mathrm{Ca}^{2+}$ signal has subsided [108]. This indicates the presence of a 'trapping' mechanism [155]. Short-term retention of CaMKII at the PSD is dependent on phosphorylation of T286 as the non-phosphorylated T286A mutant dissociates over the same time course as the $\mathrm{Ca}^{2+}$ signal, whereas phosphomimetic T286D forms persistent puncta [155]. Mass spectrometry also shows that CaMKII phosphorylated at T286 is enriched in the PSD fraction, whereas CaMKII phosphorylated at T306 is predominantly cytosolic [156]. Together, these results paint a picture of diffuse CaMKII being recruited to the PSD upon NMDA-receptor stimulation, and remaining partially PSD-localised over long time periods. But what is the structural and molecular basis of this behaviour?

Activation of CaMKII enables the kinase to bind to the C-terminus of 
NMDARs, and also increases the affinity of the holoenzyme for densin180. Quantitative MS experiments reveal that GluN2B subunits are present in the PSD at approximately twice the abundance of densin180 , with the two together accounting for $\sim 70$ potential CaMKII anchoring sites per PSD [136]. Functional experiments are consistent with the more abundant GluN2B subunit C-terminal tail playing a key role in localising CaMKII at the PSD during LTP. In heterologous expression systems, diffuse CaMKII becomes punctate and co-localises with NMDARs upon NMDAR activation [99] in $\mathrm{a} \mathrm{Ca}^{2+}$-dependent manner $[102,104,157]$. In transgenic mice, induced expression of the C-terminal tail of GluN2B (839-1482) effectively chelates existing CaMKII and disrupts existing CaMKII/GluN2B interactions, leading to reduced T286 autophosphorylation, reduced AMPA receptor phosphorylation, impaired LTP, and learning defects [158]. Furthermore, knock-in point mutations that disrupt the distal CaMKII anchoring site within the GluN2B subunit produce similar effects [159]. Binding to the NMDAR is thought to both enhance local phosphorylation by the kinase, and sustain the activity of the kinase. Experiments in HEK cells using a chimeric GluN2B construct fused with a CaMKII-substrate confirm that anchoring to the NMDAR increases CaMKII activity in the immediate vicinity of the anchoring site [160]. Binding of CaMKII to GluN2B inhibits phosphorylation of T305 and T306 by reducing the dissociation rate of CaM [104]. Moreover, when bound to GluN2B, CaMKII retains about $30 \%$ of its autonomous activity, in a manner independent of both T286 phosphorylation and CaM binding [104].

CaMKII dissociation from actin and actinin during LTP induction is thought to be critical for coupling changes in synaptic strength driven by AMPAR incorporation to modifications in the actin substructure of the spine [12]. Chemically-induced LTP leads to a marked decrease in CaMKII mobility not only inside the PSD but within $\sim 600 \mathrm{~nm}$ of the structure extending into the spine [161]. This is perhaps surprising as CaMKII mobility might be expected to increase inside the spine after release from the actin cytoskeleton outside of the PSD. One potential explanation, consistent with the known stabilization of the actin cytoskeleton during LTP [162], is that release of CaMKII triggers higher rates of actin polymerization and branching that enable actin to act as a more effective 'sieve' to slow CaMKII diffusion. Clearly, there is still much to learn about CaMKII interplay with actin, actinin, and other cytoskeletal regulators [162]. How might active CaMKII be coordinated within the PSD? Identification of ring-shaped objects corresponding to CaMKII association domains within isolated PSDs using electron tomography [163] show that CaMKII dodecamers can embed within the core matrix of the PSD, in addition to a more prevalent anchoring site in the pallium $[137,163]$. It is difficult to be certain of the location of densin-180. It has been shown to interact with SHANK [151], which resides within the pallium, but its palmitoyltated N-terminus is also thought to associate with the postsynaptic membrane. The location of the NMDAR C-terminus is less ambiguous. Interaction between the Cterminus of NMDARs and the second PDZ domain of PSD-95 is compatible with the known vertical geometry of PSD-95, and places the Ctermini of NMDAR GluN2A/B subunits (grey, Fig. $4 \mathrm{~b}$ ) $\sim 8 \mathrm{~nm}$ from the

a Naïve synapse conformation membrane [115], and presumably very close to the mouth of the channel. Both CaMKII and the overall PSD are disc shaped. In representations of CaMKII association with the PSD, the two discs are usually arranged in parallel. However, orthogonally-angled CaMKII dodecamers might be able to bridge both the core NMDAR association site, and sites within the pallium (Fig. 4b). Electron tomography has revealed that both vertical filaments [117] and ionotropic glutamate receptors [135] are tightly packed in the PSD, with vertical filaments separated on average by only $14 \mathrm{~nm}$ [117]. Orthogonal insertion of CaMKII would therefore enable kinase domains to access NMDAR tails without major reorganisation of the tightly packed vertical filament framework of the PSD.

The importance of cooperative interactions through different protomers engaging different proteins is highlighted by experiments with monomeric CaMKII. Deletion mutants of CaMKIIa that lack the association domain, despite retaining the ability to become autonomously active, do not bind to immobilised fragments of the distal GluN2B region [102] and fail to accumulate at the PSD in neurons [108]. Moreover, GluN2B and other CaMKII interaction partners do not compete for binding to CaMKII [96], and thus the holoenzyme may act as a 'bridge' between different anchors in the PSD. Recent studies have established that abundant PSD scaffold proteins, including SynGAP and AIDA-1, move from the core to the pallium during LTP [121]. Conceivably, this could create space for insertion of CaMKII within the PSD core, although this remains to be tested. Finally, it is important to consider the implications of anchoring part of CaMKII within the immediate vicinity of the NMDAR receptor. Access to $\mathrm{Ca}^{2+}$ microdomains centered on NMDAR subunits, which would not activate CaMKII prior to localization, likely contribute to the sustained long-term association of a fraction of the kinase following the induction of LTP. In addition, the CaMKII holoenzyme is so large that it is likely that different kinase domains within a single dodecamer will respond differently to $\mathrm{Ca}^{2+}$ entry through NMDARs. This could support coordination mechanisms in which active and inactive CaMKII protomers within the same dodecamer engage in different types of protein-protein interaction. For example, active kinase domains in proximity to the postsynaptic membrane may bind NMDARs while, within the same CaMKII dodecamer, regulatory elements of inactive protomers lying nearer the pallium interact with actin and $\alpha$-actinin (Fig. 4b).

\section{Concluding remarks}

In this review, we have considered how the precise positioning of calcineurin and CaMKII in dendritic spines underlies their ability to drive long-lasting changes in synaptic strength and spine morphology. Some important differences in the targeting of the two enzymes are emerging. Current evidence suggests that in naïve synapses calcineurin, but not CaMKII, is anchored in close proximity to NMDARs (Fig. 5a). Their different initial proximity to NMDARs may support activation of calcineurin but not CaMKII within restricted $\mathrm{Ca}^{2+}$ microdomains emanating from NMDARs during the induction of LTD. LTP triggers an

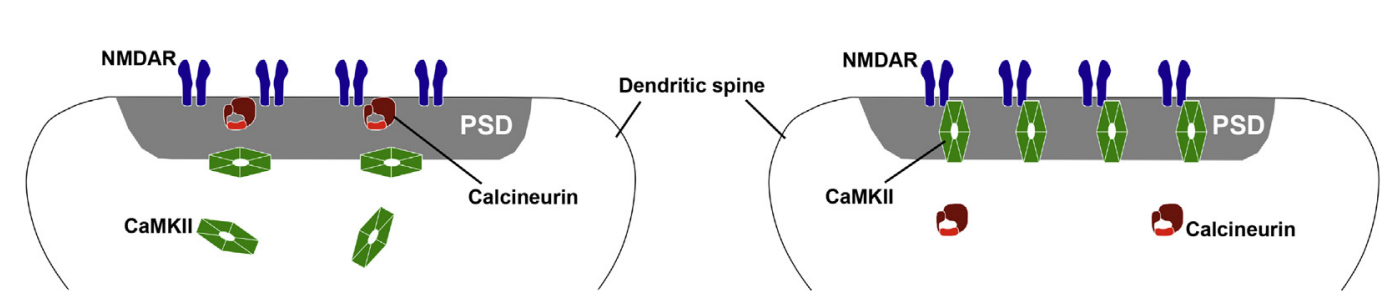

Fig. 5. Summary model of calcineurin and CaMKII coordination in naïve and potentiated spines. This simplified model shows calcineurin (red) and CaMKII (green) positioning in naïve (a) and recently potentiated (b) dendritic spines. The model highlights positioning relative to NMDARs (blue), which are the major $\mathrm{Ca}^{2+}$ entry point within the PSD. (For interpretation of the references to colour in this figure legend, the reader is referred to the web version of this article.) 
approximate inversion of this anchoring pattern (Fig. 5b). Large influxes of $\mathrm{Ca}^{2+}$ during LTP induction trigger relocation of AKAP79 out of the PSD, which may shield substrates including AMPAR GluA1 subunits from calcineurin dephosphorylation. Furthermore, binding of CaMKII to the C-terminal tails of NMDARs likely contributes to enduring CaMKII activity in part by enabling the kinase to respond to local elevations of $\mathrm{Ca}^{2+}$ close to the receptor mouth. However, it is difficult to be confident in these proposed mechanisms without answering several outstanding structural questions regarding CaMKII and calcineurin in dendritic spines. Notably, there is no high-resolution structural data revealing how CaMKII associates with any of actin, $\alpha$-actinin, densin180 , or its proximal interaction site in NMDARs. CaMKII associates with $\alpha$-actinin in the absence of $\mathrm{Ca}^{2+}$, but it is not clear whether this interaction supports CaMKII localization outside of the PSD, within the PSD pallium, or the core PSD. There is no information relating to densin-180 coordination within the PSD besides a reported interaction with the horizontal filament protein SHANK. Further outstanding topics include determining how actin and $\alpha$-actinin assemble with mixed CaMKII $\alpha / \beta$ holoenzymes, and understanding how release of CaMKII from $\alpha$-actinin is coupled to changes in the actin sub-structure of the spine during LTP. Finally, little effort has been made to search for LxVPtype calcineurin-interacting proteins that could associate with the phosphatase during LTP.

Technical advances in recent years should support efforts to resolve these outstanding questions. For example, super-resolution microscopy [116], and cross-linking coupled to mass spectrometry [164], may enable the positions of calcineurin and CaMKII complexes to be more accurately assigned within intact PSDs. Progress is also likely to be supported by determining structures of purified multi-protein subcomplexes involving CaMKII by single-particle cryo-electron microscopy, an approach that has also developed rapidly in the last decade [165]. In the long-term, insight may also be gained by incorporating a temporal component into structural models to understand how both the amplitude and timing of $\mathrm{Ca}^{2+}$ influxes affect CaMKII and calcineurin interactions in dendritic spines. Calcineurin [166], CaMKII [167,168], and their associated anchoring proteins [169] are emerging as important players in the development of neurological diseases. This should spur on efforts to understand how these remarkable enzymes regulate synaptic strength and the shape of dendritic spines at the structural and molecular level.

\section{Acknowledgements}

MGG is a Wellcome Trust and Royal Society Sir Henry Dale fellow (104194/Z/14/Z), and receives support from the BBSRC (BB/ N015274/1). We would like to thank Tim Church and Ashton Curtis for critical appraisal of the manuscript.

\section{References}

[1] R.C. Malenka, M.F. Bear, LTP and LTD: an embarrassment of riches, Neuron 44 (1) (2004) 5-21.

[2] J.A. Cummings, R.M. Mulkey, R.A. Nicoll, R.C. Malenka, Ca2 + signaling requirements for long-term depression in the hippocampus, Neuron 16 (4) (1996) $825-833$.

[3] D.E. Feldman, The spike-timing dependence of plasticity, Neuron 75 (4) (2012) 556-571.

[4] T. Kuno, H. Mukai, A. Ito, C.D. Chang, K. Kishima, N. Saito, C. Tanaka, Distinct cellular expression of calcineurin a alpha and a beta in rat brain, J. Neurochem. 58 (5) (1992) 1643-1651.

[5] N.E. Erondu, M.B. Kennedy, Regional distribution of type II Ca2 +/calmodulindependent protein kinase in rat brain, J. Neurosci. 5 (12) (1985) 3270-3277.

[6] V. Anggono, R.L. Huganir, Regulation of AMPA receptor trafficking and synaptic plasticity, Curr. Opin. Neurobiol. 22 (3) (2012) 461-469.

[7] H. Zeng, S. Chattarji, M. Barbarosie, L. Rondi-Reig, B.D. Philpot, T. Miyakawa, M.F. Bear, S. Tonegawa, Forebrain-specific calcineurin knockout selectively impairs bidirectional synaptic plasticity and working/episodic-like memory, Cell 107 (5) (2001) 617-629.

[8] R.M. Mulkey, S. Endo, S. Shenolikar, R.C. Malenka, Involvement of a calcineurin/ inhibitor-1 phosphatase cascade in hippocampal long-term depression, Nature 369
(6480) (1994) 486-488.

[9] J. Lisman, R. Yasuda, S. Raghavachari, Mechanisms of CaMKII action in long-term potentiation, Nat. Rev. Neurosci. 13 (3) (2012) 169-182.

[10] K.P. Giese, N.B. Fedorov, R.K. Filipkowski, A.J. Silva, Autophosphorylation at Thr286 of the alpha calcium-calmodulin kinase II in LTP and learning, Science 279 (5352) (1998) 870-873.

[11] P.M. Lledo, G.O. Hjelmstad, S. Mukherji, T.R. Soderling, R.C. Malenka, R.A. Nicoll, Calcium/calmodulin-dependent kinase II and long-term potentiation enhance synaptic transmission by the same mechanism, Proc. Natl. Acad. Sci. U. S. A. 92 (24) (1995) 11175-11179.

[12] J.W. Hell, CaMKII: claiming center stage in postsynaptic function and organization, Neuron 81 (2) (2014) 249-265.

[13] M.F. Bear, Bidirectional synaptic plasticity: from theory to reality, Philos. Trans. R. Soc. Lond. Ser. B Biol. Sci. 358 (1432) (2003) 649-655.

[14] M.M. Stratton, L.H. Chao, H. Schulman, J. Kuriyan, Structural studies on the regulation of $\mathrm{Ca} 2+$ /calmodulin dependent protein kinase II, Curr. Opin. Struct. Biol. 23 (2) (2013) 292-301.

[15] P.M. Stemmer, C.B. Klee, Dual calcium ion regulation of calcineurin by calmodulin and calcineurin B, Biochemistry 33 (22) (1994) 6859-6866.

[16] Y. Chen, B.L. Sabatini, Signaling in dendritic spines and spine microdomains, Curr. Opin. Neurobiol. 22 (3) (2012) 389-396.

[17] S.J. Lee, Y. Escobedo-Lozoya, E.M. Szatmari, R. Yasuda, Activation of CaMKII in single dendritic spines during long-term potentiation, Nature 458 (7236) (2009) 299-304.

[18] G. Lynch, J. Larson, S. Kelso, G. Barrionuevo, F. Schottler, Intracellular injections of EGTA block induction of hippocampal long-term potentiation, Nature 305 (5936) (1983) 719-721.

[19] S.C. Harney, M. Rowan, R. Anwyl, Long-term depression of NMDA receptormediated synaptic transmission is dependent on activation of metabotropic glutamate receptors and is altered to long-term potentiation by low intracellular calcium buffering, J. Neurosci. 26 (4) (2006) 1128-1132.

[20] I.E. Dick, M.R. Tadross, H. Liang, L.H. Tay, W. Yang, D.T. Yue, A modular switch for spatial $\mathrm{Ca} 2+$ selectivity in the calmodulin regulation of $\mathrm{CaV}$ channels, Nature 451 (7180) (2008) 830-834.

[21] C.J. Penny, B.S. Kilpatrick, E.R. Eden, S. Patel, Coupling acidic organelles with the ER through $\mathrm{ca}(2)(+)$ microdomains at membrane contact sites, Cell Calcium 58 (4) (2015) 387-396.

[22] M.G. Gold, T. Gonen, J.D. Scott, Local cAMP signaling in disease at a glance, J. Cell Sci. 126 (Pt 20) (2013) 4537-4543.

[23] C.R. Kissinger, H.E. Parge, D.R. Knighton, C.T. Lewis, L.A. Pelletier, A. Tempczyk, V.J. Kalish, K.D. Tucker, R.E. Showalter, E.W. Moomaw, et al., Crystal structures of human calcineurin and the human FKBP12-FK506-calcineurin complex, Nature 378 (6557) (1995) 641-644.

[24] A.A. Stewart, T.S. Ingebritsen, A. Manalan, C.B. Klee, P. Cohen, Discovery of a $\mathrm{Ca} 2+-$ and calmodulin-dependent protein phosphatase: probable identity with calcineurin (CaM-BP80), FEBS Lett. 137 (1) (1982) 80-84.

[25] H. Li, A. Rao, P.G. Hogan, Interaction of calcineurin with substrates and targeting proteins, Trends Cell Biol. 21 (2) (2011) 91-103.

[26] N. Patel, F. Stengel, R. Aebersold, M.G. Gold, Molecular basis of AKAP79 regulation by calmodulin, Nat. Commun. 8 (1) (2017) 1681.

[27] A.R. Quintana, D. Wang, J.E. Forbes, M.N. Waxham, Kinetics of calmodulin binding to calcineurin, Biochem. Biophys. Res. Commun. 334 (2) (2005) 674-680.

[28] S. Kakiuchi, S. Yasuda, R. Yamazaki, Y. Teshima, K. Kanda, R. Kakiuchi, K. Sobue, Quantitative determinations of calmodulin in the supernatant and particulate fractions of mammalian tissues, J. Biochem. 92 (4) (1982) 1041-1048.

[29] J. Aramburu, F. Garcia-Cozar, A. Raghavan, H. Okamura, A. Rao, P.G. Hogan, Selective inhibition of NFAT activation by a peptide spanning the calcineurin targeting site of NFAT, Mol. Cell 1 (5) (1998) 627-637.

[30] J. Aramburu, M.B. Yaffe, C. Lopez-Rodriguez, L.C. Cantley, P.G. Hogan, A. Rao, Affinity-driven peptide selection of an NFAT inhibitor more selective than cyclosporin a, Science 285 (5436) (1999) 2129-2133.

[31] H. Li, A. Rao, P.G. Hogan, Structural delineation of the calcineurin-NFAT interaction and its parallels to PP1 targeting interactions, J. Mol. Biol. 342 (5) (2004) 1659-1674.

[32] H. Li, L. Zhang, A. Rao, S.C. Harrison, P.G. Hogan, Structure of calcineurin in complex with PVIVIT peptide: portrait of a low-affinity signalling interaction, J. Mol. Biol. 369 (5) (2007) 1296-1306.

[33] M.G. Gold, B. Lygren, P. Dokurno, N. Hoshi, G. McConnachie, K. Tasken, C.R. Carlson, J.D. Scott, D. Barford, Molecular basis of AKAP specificity for PKA regulatory subunits, Mol. Cell 24 (3) (2006) 383-395.

[34] F.S. Kinderman, C. Kim, S. von Daake, Y. Ma, B.Q. Pham, G. Spraggon, N. H. Xuong, P.A. Jennings, S.S. Taylor, A dynamic mechanism for AKAP binding to RII isoforms of cAMP-dependent protein kinase, Mol. Cell 24 (3) (2006) 397-408.

[35] J. Roy, H. Li, P.G. Hogan, M.S. Cyert, A conserved docking site modulates substrate affinity for calcineurin, signaling output, and in vivo function, Mol. Cell 25 (6) (2007) 889-901.

[36] D.W. Carr, R.E. Stofko-Hahn, I.D. Fraser, R.D. Cone, J.D. Scott, Localization of the cAMP-dependent protein kinase to the postsynaptic densities by A-kinase anchoring proteins. Characterization of AKAP 79, J. Biol. Chem. 267 (24) (1992) 16816-16823.

[37] V.M. Coghlan, B.A. Perrino, M. Howard, L.K. Langeberg, J.B. Hicks, W.M. Gallatin, J.D. Scott, Association of protein kinase a and protein phosphatase $2 \mathrm{~B}$ with a common anchoring protein, Science 267 (5194) (1995) 108-111.

[38] M.L. Dell'Acqua, K.L. Dodge, S.J. Tavalin, J.D. Scott, Mapping the protein phosphatase-2B anchoring site on AKAP79. Binding and inhibition of phosphatase activity are mediated by residues 315-360, J. Biol. Chem. 277 (50) (2002) 
48796-48802.

[39] H. Li, M.D. Pink, J.G. Murphy, A. Stein, M.L. Dell'Acqua, P.G. Hogan, Balanced interactions of calcineurin with AKAP79 regulate Ca2 + - calcineurin-NFAT signaling, Nat. Struct. Mol. Biol. 19 (3) (2012) 337-345.

[40] M.G. Gold, F. Stengel, P.J. Nygren, C.R. Weisbrod, J.E. Bruce, C.V. Robinson, D. Barford, J.D. Scott, Architecture and dynamics of an A-kinase anchoring protein 79 (AKAP79) signaling complex, Proc. Natl. Acad. Sci. U. S. A. 108 (16) (2011) 6426-6431.

[41] P.J. Nygren, S. Mehta, D.K. Schweppe, L.K. Langeberg, J.L. Whiting, C.R. Weisbrod, J.E. Bruce, J. Zhang, D. Veesler, J.D. Scott, Intrinsic disorder within AKAP79 fine-tunes anchored phosphatase activity toward substrates and drug sensitivity, elife 6 (2017).

[42] S. Park, M. Uesugi, G.L. Verdine, A second calcineurin binding site on the NFAT regulatory domain, Proc. Natl. Acad. Sci. U. S. A. 97 (13) (2000) 7130-7135.

[43] J. Liu, K. Arai, N. Arai, Inhibition of NFATx activation by an oligopeptide: disrupting the interaction of NFATx with calcineurin, J. Immunol. 167 (5) (2001) 2677-2687.

[44] A. Rodriguez, J. Roy, S. Martinez-Martinez, M.D. Lopez-Maderuelo, P. NinoMoreno, L. Orti, D. Pantoja-Uceda, A. Pineda-Lucena, M.S. Cyert, J.M. Redondo, A conserved docking surface on calcineurin mediates interaction with substrates and immunosuppressants, Mol. Cell 33 (5) (2009) 616-626.

[45] S. Grigoriu, R. Bond, P. Cossio, J.A. Chen, N. Ly, G. Hummer, R. Page, M.S. Cyert, W. Peti, The molecular mechanism of substrate engagement and immunosuppressant inhibition of calcineurin, PLoS Biol. 11 (2) (2013) e1001492.

[46] S.R. Sheftic, R. Page, W. Peti, Investigating the human Calcineurin interaction network using the piLxVP SLiM, Sci. Rep. 6 (2016) 38920.

[47] M.K. Bennett, N.E. Erondu, M.B. Kennedy, Purification and characterization of calmodulin-dependent protein kinase that is highly concentrated in brain, J. Biol. Chem. 258 (20) (1983) 12735-12744.

[48] J.R. Woodgett, M.T. Davison, P. Cohen, The calmodulin-dependent glycogen synthase kinase from rabbit skeletal muscle. Purification, subunit structure and substrate specificity, Eur. J. Biochem. 136 (3) (1983) 481-487.

[49] T. Kanaseki, Y. Ikeuchi, H. Sugiura, T. Yamauchi, Structural features of Ca2+/ calmodulin-dependent protein kinase II revealed by electron microscopy, J. Cell Biol. 115 (4) (1991) 1049-1060.

[50] E.P. Morris, K. Torok, Oligomeric structure of alpha-calmodulin-dependent protein kinase II, J. Mol. Biol. 308 (1) (2001) 1-8.

[51] J.B. Myers, V. Zaegel, S.J. Coultrap, A.P. Miller, K.U. Bayer, S.L. Reichow, The CaMKII holoenzyme structure in activation-competent conformations, Nat. Commun. 8 (2017) 15742.

[52] L.H. Chao, M.M. Stratton, I.H. Lee, O.S. Rosenberg, J. Levitz, D.J. Mandell, T. Kortemme, J.T. Groves, H. Schulman, J. Kuriyan, A mechanism for tunable autoinhibition in the structure of a human Ca2 + /calmodulin- dependent kinase II holoenzyme, Cell 146 (5) (2011) 732-745.

[53] S.J. Kolodziej, A. Hudmon, M.N. Waxham, J.K. Stoops, Three-dimensional reconstructions of calcium/calmodulin-dependent (CaM) kinase IIalpha and truncated CaM kinase IIalpha reveal a unique organization for its structural core and functional domains, J. Biol. Chem. 275 (19) (2000) 14354-14359.

[54] M. Bhattacharyya, M.M. Stratton, C.C. Going, E.D. McSpadden, Y. Huang, A.C. Susa, A. Elleman, Y.M. Cao, N. Pappireddi, P. Burkhardt, C.L. Gee, T. Barros, H. Schulman, E.R. Williams, J. Kuriyan, Molecular mechanism of activation-triggered subunit exchange in $\mathrm{Ca}(2+)$ /calmodulin-dependent protein kinase II, eLife 5 (2016) e13405.

[55] S.G. Miller, M.B. Kennedy, Distinct forebrain and cerebellar isozymes of type II $\mathrm{Ca} 2+/$ calmodulin-dependent protein kinase associate differently with the postsynaptic density fraction, J. Biol. Chem. 260 (15) (1985) 9039-9046.

[56] R.M. Tombes, M.O. Faison, J.M. Turbeville, Organization and evolution of multifunctional ca(2+)/CaM-dependent protein kinase genes, Gene 322 (2003) $17-31$.

[57] T.R. Gaertner, S.J. Kolodziej, D. Wang, R. Kobayashi, J.M. Koomen, J.K. Stoops, M.N. Waxham, Comparative analyses of the three-dimensional structures and enzymatic properties of alpha, beta, gamma and delta isoforms of Ca2 + - calmodulin-dependent protein kinase II, J. Biol. Chem. 279 (13) (2004) 12484-12494.

[58] L. Brocke, L.W. Chiang, P.D. Wagner, H. Schulman, Functional implications of the subunit composition of neuronal CaM kinase II, J. Biol. Chem. 274 (32) (1999) 22713-22722.

[59] O.S. Rosenberg, S. Deindl, R.J. Sung, A.C. Nairn, J. Kuriyan, Structure of the autoinhibited kinase domain of CaMKII and SAXS analysis of the holoenzyme, Cell 123 (5) (2005) 849-860.

[60] M. Stratton, I.H. Lee, M. Bhattacharyya, S.M. Christensen, L.H. Chao, H. Schulman, J.T. Groves, J. Kuriyan, Activation-triggered subunit exchange between CaMKII holoenzymes facilitates the spread of kinase activity, elife 3 (2013) e01610.

[61] W.E. Meador, A.R. Means, F.A. Quiocho, Modulation of calmodulin plasticity in molecular recognition on the basis of x-ray structures, Science 262 (5140) (1993) 1718-1721.

[62] P.I. Hanson, T. Meyer, L. Stryer, H. Schulman, Dual role of calmodulin in autop hosphorylation of multifunctional CaM kinase may underlie decoding of calcium signals, Neuron 12 (5) (1994) 943-956.

[63] R.C. Rich, H. Schulman, Substrate-directed function of calmodulin in autophosphorylation of Ca2 +/calmodulin-dependent protein kinase II, J. Biol. Chem. 273 (43) (1998) 28424-28429.

[64] S.G. Miller, B.L. Patton, M.B. Kennedy, Sequences of autophosphorylation sites in neuronal type II CaM kinase that control Ca2(+)-independent activity, Neuron 1 (7) (1988) 593-604.

[65] C.M. Schworer, R.J. Colbran, J.R. Keefer, T.R. Soderling, Ca2 +/calmodulin- dependent protein kinase II. Identification of a regulatory autophosphorylation site adjacent to the inhibitory and calmodulin-binding domains, J. Biol. Chem. 263 (27) (1988) 13486-13489.

[66] G. Thiel, A.J. Czernik, F. Gorelick, A.C. Nairn, P. Greengard, Ca2 +/calmodulindependent protein kinase II: identification of threonine-286 as the autophosphorylation site in the alpha subunit associated with the generation of Ca2 + -independent activity, Proc. Natl. Acad. Sci. U. S. A. 85 (17) (1988) 6337-6341.

[67] K. Barcomb, I. Buard, S.J. Coultrap, J.R. Kulbe, T.A. O'Leary, K.U. Bayer Benke, Autonomous CaMKII requires further stimulation by $\mathrm{Ca} 2+/$ calmodulin for enhancing synaptic strength, FASEB J. 28 (8) (2014) 3810-3819.

[68] P. De Koninck, H. Schulman, Sensitivity of CaM kinase II to the frequency of Ca2 + oscillations, Science 279 (5348) (1998) 227-230.

[69] J.M. Bradshaw, Y. Kubota, T. Meyer, H. Schulman, An ultrasensitive Ca2 + /calmodulin-dependent protein kinase II-protein phosphatase 1 switch facilitates specificity in postsynaptic calcium signaling, Proc. Natl. Acad. Sci. U. S. A. 100 (18) (2003) 10512-10517.

[70] L.L. Lou, H. Schulman, Distinct autophosphorylation sites sequentially produce autonomy and inhibition of the multifunctional $\mathrm{Ca} 2+$ /calmodulin-dependent protein kinase, J. Neurosci. 9 (6) (1989) 2020-2032.

[71] Y. Elgersma, N.B. Fedorov, S. Ikonen, E.S. Choi, M. Elgersma, O.M. Carvalho, K.P. Giese, A.J. Silva, Inhibitory autophosphorylation of CaMKII controls PSD association, plasticity, and learning, Neuron 36 (3) (2002) 493-505.

[72] A. Hoelz, A.C. Nairn, J. Kuriyan, Crystal structure of a tetradecameric assembly of the association domain of Ca2 + /calmodulin-dependent kinase II, Mol. Cell 11 (5) (2003) 1241-1251.

[73] S. Strack, A.J. Robison, M.A. Bass, R.J. Colbran, Association of calcium/calmodulin-dependent kinase II with developmentally regulated splice variants of the postsynaptic density protein densin-180, J. Biol. Chem. 275 (33) (2000) 25061-25064.

[74] R.S. Walikonis, A. Oguni, E.M. Khorosheva, C.J. Jeng, F.J. Asuncion, M.B. Kennedy, Densin-180 forms a ternary complex with the (alpha)-subunit of Ca2 + /calmodulin-dependent protein kinase II and (alpha)-actinin, J. Neurosci. 21 (2) (2001) 423-433.

[75] M.L. Apperson, I.S. Moon, M.B. Kennedy, Characterization of densin-180, a new brain-specific synaptic protein of the O-sialoglycoprotein family, J. Neurosci. 16 (21) (1996) 6839-6852.

[76] A. Thalhammer, J.C. Trinidad, A.L. Burlingame, R. Schoepfer, Densin-180: revised membrane topology, domain structure and phosphorylation status, J. Neurochem. 109 (2) (2009) 297-302.

[77] D.C. Liu, G.M. Jow, C.C. Chuang, Y.J. Peng, P.H. Hsu, C.Y. Tang, Densin-180 is not a transmembrane protein, Cell Biochem. Biophys. 67 (2) (2013) 773-783.

[78] I. Izawa, M. Nishizawa, Y. Hayashi, M. Inagaki, Palmitoylation of ERBIN is required for its plasma membrane localization, Genes Cells 13 (7) (2008) 691-701.

[79] P. Rellos, A.C. Pike, F.H. Niesen, E. Salah, W.H. Lee, F. von Delft, S. Knapp, Structure of the CaMKIIdelta/calmodulin complex reveals the molecular mechanism of CaMKII kinase activation, PLoS Biol. 8 (7) (2010) e1000426.

[80] R.J. Colbran, Y.L. Fong, C.M. Schworer, T.R. Soderling, Regulatory interactions of the calmodulin-binding, inhibitory, and autophosphorylation domains of $\mathrm{Ca} 2+1$ calmodulin-dependent protein kinase II, J. Biol. Chem. 263 (34) (1988) $18145-18151$

[81] L.H. Chao, P. Pellicena, S. Deindl, L.A. Barclay, H. Schulman, J. Kuriyan, Intersubunit capture of regulatory segments is a component of cooperative CaMKII activation, Nat. Struct. Mol. Biol. 17 (3) (2010) 264-272.

[82] T. Meyer, P.I. Hanson, L. Stryer, H. Schulman, Calmodulin trapping by calciumcalmodulin-dependent protein kinase, Science 256 (5060) (1992) 1199-1202.

[83] P.I. Hanson, H. Schulman, Inhibitory autophosphorylation of multifunctional $\mathrm{Ca} 2+$ /calmodulin-dependent protein kinase analyzed by site-directed mutagenesis, J. Biol. Chem. 267 (24) (1992) 17216-17224.

[84] B.L. Patton, S.G. Miller, M.B. Kennedy, Activation of type II calcium/calmodulindependent protein kinase by $\mathrm{Ca} 2+/$ calmodulin is inhibited by autophosphorylation of threonine within the calmodulin-binding domain, J. Biol. Chem. 265 (19) (1990) 11204-11212.

[85] K. Shen, M.N. Teruel, K. Subramanian, T. Meyer, CaMKIIbeta functions as an Factin targeting module that localizes CaMKIIalpha/beta heterooligomers to dendritic spines, Neuron 21 (3) (1998) 593-606.

[86] H. O'Leary, E. Lasda, K.U. Bayer, CaMKIIbeta association with the actin cytoskeleton is regulated by alternative splicing, Mol. Biol. Cell 17 (11) (2006) 4656-4665.

[87] K. Okamoto, R. Narayanan, S.H. Lee, K. Murata, Y. Hayashi, The role of CaMKII as an F-actin-bundling protein crucial for maintenance of dendritic spine structure, Proc. Natl. Acad. Sci. U. S. A. 104 (15) (2007) 6418-6423.

[88] Y.C. Lin, L. Redmond, CaMKIIbeta binding to stable F-actin in vivo regulates Factin filament stability, Proc. Natl. Acad. Sci. U. S. A. 105 (41) (2008) 15791-15796.

[89] C.C. Fink, K.U. Bayer, J.W. Myers, J.E. Ferrell Jr., H. Schulman, T. Meyer, Selective regulation of neurite extension and synapse formation by the beta but not the alpha isoform of CaMKII, Neuron 39 (2) (2003) 283-297.

[90] A. Rao, E. Kim, M. Sheng, A.M. Craig, Heterogeneity in the molecular composition of excitatory postsynaptic sites during development of hippocampal neurons in culture, J. Neurosci. 18 (4) (1998) 1217-1229.

[91] A.W. Dunah, M. Wyszynski, D.M. Martin, M. Sheng, D.G. Standaert, Alpha-actinin2 in rat striatum: localization and interaction with NMDA glutamate recepto subunits, Brain Res. Mol. Brain Res. 79 (1-2) (2000) 77-87.

[92] M. Wyszynski, V. Kharazia, R. Shanghvi, A. Rao, A.H. Beggs, A.M. Craig, R. Weinberg, M. Sheng, Differential regional expression and ultrastructural 
localization of alpha-actinin-2, a putative NMDA receptor-anchoring protein, in rat brain, J. Neurosci. 18 (4) (1998) 1383-1392.

[93] N. Jalan-Sakrikar, R.K. Bartlett, A.J. Baucum, R.J. Colbran 2nd, Substrate-selective and calcium-independent activation of CaMKII by alpha-actinin, J. Biol. Chem. 287 (19) (2012) 15275-15283.

[94] A.J. Robison, R.K. Bartlett, M.A. Bass, R.J. Colbran, Differential modulation of $\mathrm{Ca} 2+/$ calmodulin-dependent protein kinase II activity by regulated interactions with N-methyl-D-aspartate receptor NR2B subunits and alpha-actinin, J. Biol. Chem. 280 (47) (2005) 39316-39323.

[95] P. Paoletti, C. Bellone, Q. Zhou, NMDA receptor subunit diversity: impact on receptor properties, synaptic plasticity and disease, Nat. Rev. Neurosci. 14 (6) (2013) 383-400.

[96] A.J. Robison, M.A. Bass, Y. Jiao, L.B. MacMillan, L.C. Carmody, R.K. Bartlett, R.J. Colbran, Multivalent interactions of calcium/calmodulin-dependent protein kinase II with the postsynaptic density proteins NR2B, densin-180, and alpha-actinin-2, J. Biol. Chem. 280 (42) (2005) 35329-35336.

[97] Y. Jiao, N. Jalan-Sakrikar, A.J. Robison, A.J. Baucum, M.A. Bass 2nd, R.J. Colbran, Characterization of a central Ca2 + /calmodulin-dependent protein kinase IIalpha/ beta binding domain in densin that selectively modulates glutamate receptor subunit phosphorylation, J. Biol. Chem. 286 (28) (2011) 24806-24818.

[98] R.B. McNeill, R.J. Colbran, Interaction of autophosphorylated Ca2 +/calmodulindependent protein kinase II with neuronal cytoskeletal proteins. Characterization of binding to a 190-kDa postsynaptic density protein, J. Biol. Chem. 270 (17) (1995) 10043-10049.

[99] S. Strack, R.J. Colbran, Autophosphorylation-dependent targeting of calcium/ calmodulin-dependent protein kinase II by the NR2B subunit of the N-methyl- Daspartate receptor, J. Biol. Chem. 273 (33) (1998) 20689-20692.

[100] H. Husi, M.A. Ward, J.S. Choudhary, W.P. Blackstock, S.G. Grant, Proteomic analysis of NMDA receptor-adhesion protein signaling complexes, Nat. Neurosci. 3 (7) (2000) 661-669.

[101] A.S. Leonard, I.A. Lim, D.E. Hemsworth, M.C. Horne, J.W. Hell, Calcium/calmodulin-dependent protein kinase II is associated with the N-methyl-D-aspartate receptor, Proc. Natl. Acad. Sci. U. S. A. 96 (6) (1999) 3239-3244.

[102] S. Strack, R.B. McNeill, R.J. Colbran, Mechanism and regulation of calcium/calmodulin-dependent protein kinase II targeting to the NR2B subunit of the N-methyl-D-aspartate receptor, J. Biol. Chem. 275 (31) (2000) 23798-23806.

[103] R.V. Omkumar, M.J. Kiely, A.J. Rosenstein, K.T. Min, M.B. Kennedy, Identification of a phosphorylation site for calcium/calmodulindependent protein kinase II in the NR2B subunit of the N-methyl-D-aspartate receptor, J. Biol. Chem. 271 (49) (1996) 31670-31678.

[104] K.U. Bayer, P. De Koninck, A.S. Leonard, J.W. Hell, H. Schulman, Interaction with the NMDA receptor locks CaMKII in an active conformation, Nature 411 (6839) (2001) 801-805.

[105] A.S. Leonard, K.U. Bayer, M.A. Merrill, I.A. Lim, M.A. Shea, H. Schulman, J.W. Hell, Regulation of calcium/calmodulin-dependent protein kinase II docking to N-methyl-D-aspartate receptors by calcium/calmodulin and alpha-actinin, J. Biol. Chem. 277 (50) (2002) 48441-48448.

[106] A. Barria, R. Malinow, NMDA receptor subunit composition controls synaptic plasticity by regulating binding to CaMKII, Neuron 48 (2) (2005) 289-301.

[107] M. Mayadevi, M. Praseeda, K.S. Kumar, R.V. Omkumar, Sequence determinants on the NR2A and NR2B subunits of NMDA receptor responsible for specificity of phosphorylation by CaMKII, Biochim. Biophys. Acta 1598 (1-2) (2002) 40-45.

[108] K.U. Bayer, E. LeBel, G.L. McDonald, H. O'Leary, H. Schulman, P. De Koninck, Transition from reversible to persistent binding of CaMKII to postsynaptic sites and NR2B, J. Neurosci. 26 (4) (2006) 1164-1174.

[109] M. Sanhueza, G. Fernandez-Villalobos, I.S. Stein, G. Kasumova, P. Zhang, K.U. Bayer, N. Otmakhov, J.W. Hell, J. Lisman, Role of the CaMKII/NMDA receptor complex in the maintenance of synaptic strength, J. Neurosci. 31 (25) (2011) 9170-9178.

[110] M. Sheng, C.C. Hoogenraad, The postsynaptic architecture of excitatory synapses: a more quantitative view, Annu. Rev. Biochem. 76 (2007) 823-847.

[111] A.C. Burette, T. Lesperance, J. Crum, M. Martone, N. Volkmann, M.H. Ellisman, R.J. Weinberg, Electron tomographic analysis of synaptic ultrastructure, J. Comp. Neurol. 520 (12) (2012) 2697-2711.

[112] N.L. Rochefort, A. Konnerth, Dendritic spines: from structure to in vivo function, EMBO Rep. 13 (8) (2012) 699-708.

[113] F. Korobova, T. Svitkina, Molecular architecture of synaptic actin cytoskeleton in hippocampal neurons reveals a mechanism of dendritic spine morphogenesis, Mol. Biol. Cell 21 (1) (2010) 165-176.

[114] Y. Takumi, V. Ramirez-Leon, P. Laake, E. Rinvik, O.P. Ottersen, Different modes of expression of AMPA and NMDA receptors in hippocampal synapses, Nat. Neurosci. 2 (7) (1999) 618-624.

[115] X. Chen, C. Winters, R. Azzam, X. Li, J.A. Galbraith, R.D. Leapman, T.S. Reese, Organization of the core structure of the postsynaptic density, Proc. Natl. Acad. Sci. U. S. A. 105 (11) (2008) 4453-4458.

[116] M.G. Gold, A frontier in the understanding of synaptic plasticity: solving the structure of the postsynaptic density, BioEssays 34 (7) (2012) 599-608.

[117] X. Chen, C.D. Nelson, X. Li, C.A. Winters, R. Azzam, A.A. Sousa, R.D. Leapman, H. Gainer, M. Sheng, T.S. Reese, PSD-95 is required to sustain the molecular organization of the postsynaptic density, J. Neurosci. 31 (17) (2011) 6329-6338.

[118] D. Cheng, C.C. Hoogenraad, J. Rush, E. Ramm, M.A. Schlager, D.M. Duong, P. Xu, S.R. Wijayawardana, J. Hanfelt, T. Nakagawa, M. Sheng, J. Peng, Relative and absolute quantification of postsynaptic density proteome isolated from rat forebrain and cerebellum, Mol. Cell. Proteomics 5 (6) (2006) 1158-1170.

[119] R.S. Petralia, N. Sans, Y.X. Wang, R.J. Wenthold, Ontogeny of postsynaptic density proteins at glutamatergic synapses, Mol. Cell. Neurosci. 29 (3) (2005) 436-452.
[120] J.G. Valtschanoff, R.J. Weinberg, Laminar organization of the NMDA receptor complex within the postsynaptic density, J. Neurosci. 21 (4) (2001) 1211-1217.

[121] A. Dosemeci, R.J. Weinberg, T.S. Reese, J.H. Tao-Cheng, The postsynaptic density: there is more than meets the eye, Front Synaptic Neurosci 8 (2016) 23.

[122] H.C. Kornau, L.T. Schenker, M.B. Kennedy, P.H. Seeburg, Domain interaction between NMDA receptor subunits and the postsynaptic density protein PSD-95, Science 269 (5231) (1995) 1737-1740.

[123] A. Sik, A. Gulacsi, Y. Lai, W.K. Doyle, S. Pacia, I. Mody, T.F. Freund, Localization of the a kinase anchoring protein AKAP79 in the human hippocampus, Eur. J. Neurosci. 12 (4) (2000) 1155-1164.

[124] K.M. Woolfrey, H. O'Leary, D.J. Goodell, H.R. Robertson, E.A. Horne, S.J. Coultrap, M.L. Dell'Acqua, K.U. Bayer, CaMKII regulates the depalmitoylation and synaptic removal of the scaffold protein AKAP79/150 to mediate structural long-term depression, J. Biol. Chem. 293 (5) (2018) 1551-1567.

[125] M. Colledge, R.A. Dean, G.K. Scott, L.K. Langeberg, R.L. Huganir, J.D. Scott, Targeting of PKA to glutamate receptors through a MAGUK-AKAP complex, Neuron 27 (1) (2000) 107-119.

[126] S.F. Oliveria, M.L. Dell'Acqua, W.A. Sather, AKAP79/150 anchoring of calcineurin controls neuronal L-type Ca2 + channel activity and nuclear signaling, Neuron 55 (2) (2007) 261-275.

[127] R. Efendiev, B.K. Samelson, B.T. Nguyen, P.V. Phatarpekar, F. Baameur, J.D. Scott, C.W. Dessauer, AKAP79 interacts with multiple adenylyl cyclase (AC) isoforms and scaffolds AC5 and -6 to alpha-amino-3-hydroxyl-5-methyl-4-isoxazole-propionate (AMPA) receptors, J. Biol. Chem. 285 (19) (2010) 14450-14458.

[128] M.L. Dell'Acqua, M.C. Faux, J. Thorburn, A. Thorburn, J.D. Scott, Membranetargeting sequences on AKAP79 bind phosphatidylinositol-4, 5-bisphosphate, EMBO J. 17 (8) (1998) 2246-2260.

[129] L.L. Gomez, S. Alam, K.E. Smith, E. Horne, M.L. Dell'Acqua, Regulation of A-kinase anchoring protein 79/150-cAMP-dependent protein kinase postsynaptic targeting by NMDA receptor activation of calcineurin and remodeling of dendritic actin, J. Neurosci. 22 (16) (2002) 7027-7044.

[130] I. Delint-Ramirez, D. Willoughby, G.R. Hammond, L.J. Ayling, D.M. Cooper, Palmitoylation targets AKAP79 protein to lipid rafts and promotes its regulation of calcium-sensitive adenylyl cyclase type 8, J. Biol. Chem. 286 (38) (2011) 32962-32975.

[131] D.J. Keith, J.L. Sanderson, E.S. Gibson, K.M. Woolfrey, H.R. Robertson, K. Olszewski, R. Kang, A. El-Husseini, M.L. Dell'acqua, Palmitoylation of A-kinase anchoring protein 79/150 regulates dendritic endosomal targeting and synaptic plasticity mechanisms, J. Neurosci. 32 (21) (2012) 7119-7136.

[132] J.L. Sanderson, J.A. Gorski, E.S. Gibson, P. Lam, R.K. Freund, W.S. Chick, M.L. Dell'Acqua, AKAP150-anchored calcineurin regulates synaptic plasticity by limiting synaptic incorporation of $\mathrm{Ca} 2+-$ permeable AMPA receptors, $\mathrm{J}$. Neurosci. 32 (43) (2012) 15036-15052.

[133] B.J. Tunquist, N. Hoshi, E.S. Guire, F. Zhang, K. Mullendorff, L.K. Langeberg, J. Raber, J.D. Scott, Loss of AKAP150 perturbs distinct neuronal processes in mice, Proc. Natl. Acad. Sci. U. S. A. 105 (34) (2008) 12557-12562.

[134] Y. Lu, X.M. Zha, E.Y. Kim, S. Schachtele, M.E. Dailey, D.D. Hall, S. Strack, S.H. Green, D.A. Hoffman, J.W. Hell, A. kinase anchor protein 150, (AKAP150)associated protein kinase a limits dendritic spine density, J. Biol. Chem. 286 (30) (2011) 26496-26506.

[135] X. Chen, L. Vinade, R.D. Leapman, J.D. Petersen, T. Nakagawa, T.M. Phillips, M. Sheng, T.S. Reese, Mass of the postsynaptic density and enumeration of three key molecules, Proc. Natl. Acad. Sci. U. S. A. 102 (32) (2005) 11551-11556.

[136] M.S. Lowenthal, S.P. Markey, A. Dosemeci, Quantitative mass spectrometry measurements reveal stoichiometry of principal postsynaptic density proteins, J. Proteome Res. 14 (6) (2015) 2528-2538.

[137] J.D. Ding, M.B. Kennedy, R.J. Weinberg, Subcellular organization of camkii in rat hippocampal pyramidal neurons, J. Comp. Neurol. 521 (15) (2013) 3570-3583.

[138] J.D. Petersen, X. Chen, L. Vinade, A. Dosemeci, J.E. Lisman, T.S. Reese, Distribution of postsynaptic density (PSD)-95 and Ca2 +/calmodulin-dependent protein kinase II at the PSD, J. Neurosci. 23 (35) (2003) 11270-11278.

[139] E. Almeida Ribeiro Jr., N. Pinotsis, A. Ghisleni, A. Salmazo, P.V. Konarev, J. Kostan, B. Sjoblom, C. Schreiner, A.A. Polyansky, E.A. Gkougkoulia, M.R. Holt, F.L. Aachmann, B. Zagrovic, E. Bordignon, K.F. Pirker, D.I. Svergun, M. Gautel, K. Djinovic-Carugo, The structure and regulation of human muscle alpha-actinin, Cell 159 (6) (2014) 1447-1460.

[140] P. Young, C. Ferguson, S. Banuelos, M. Gautel, Molecular structure of the sarcomeric Z-disk: two types of titin interactions lead to an asymmetrical sorting of alpha-actinin, EMBO J. 17 (6) (1998) 1614-1624.

[141] C.K. Choi, M. Vicente-Manzanares, J. Zareno, L.A. Whitmore, A. Mogilner, A.R. Horwitz, Actin and alpha-actinin orchestrate the assembly and maturation of nascent adhesions in a myosin II motor-independent manner, Nat. Cell Biol. 10 (9) (2008) 1039-1050.

[142] D. Laporte, N. Ojkic, D. Vavylonis, J.Q. Wu, Alpha-Actinin and fimbrin cooperate with myosin II to organize actomyosin bundles during contractile-ring assembly, Mol. Biol. Cell 23 (16) (2012) 3094-3110.

[143] S. Mukhina, Y.L. Wang, M. Murata-Hori, Alpha-actinin is required for tightly regulated remodeling of the actin cortical network during cytokinesis, Dev. Cell 13 (4) (2007) 554-565.

[144] J.L. Hodges, S.M. Vilchez, H. Asmussen, L.A. Whitmore, A.R. Horwitz, AlphaActinin-2 mediates spine morphology and assembly of the post-synaptic density in hippocampal neurons, PLoS One 9 (7) (2014) e101770.

[145] K. Fukami, K. Furuhashi, M. Inagaki, T. Endo, S. Hatano, T. Takenawa, Requirement of phosphatidylinositol 4,5-bisphosphate for alpha-actinin function, Nature 359 (6391) (1992) 150-152.

[146] K. Fukami, N. Sawada, T. Endo, T. Takenawa, Identification of a 
phosphatidylinositol 4,5-bisphosphate-binding site in chicken skeletal muscle alpha-actinin, J. Biol. Chem. 271 (5) (1996) 2646-2650.

[147] T.S. Fraley, T.C. Tran, A.M. Corgan, C.A. Nash, J. Hao, D.R. Critchley, J.A. Greenwood, Phosphoinositide binding inhibits alpha-actinin bundling activity, J. Biol. Chem. 278 (26) (2003) 24039-24045.

[148] A. Ribeiro Ede Jr., N. Pinotsis, A. Ghisleni, A. Salmazo, P.V. Konarev, J. Kostan, B. Sjoblom, C. Schreiner, A.A. Polyansky, E.A. Gkougkoulia, M.R. Holt, F.L. Aachmann, B. Zagrovic, E. Bordignon, K.F. Pirker, D.I. Svergun, M. Gautel, K. Djinovic-Carugo, The structure and regulation of human muscle alpha-actinin, Cell 159 (6) (2014) 1447-1460.

[149] C.M. Hampton, D.W. Taylor, K.A. Taylor, Novel structures for alpha-actinin:Factin interactions and their implications for actin-membrane attachment and tension sensing in the cytoskeleton, J. Mol. Biol. 368 (1) (2007) 92-104.

[150] M. Wyszynski, J. Lin, A. Rao, E. Nigh, A.H. Beggs, A.M. Craig, M. Sheng, Competitive binding of alpha-actinin and calmodulin to the NMDA receptor, Nature 385 (6615) (1997) 439-442.

[151] A. Quitsch, K. Berhorster, C.W. Liew, D. Richter, H.J. Kreienkamp, Postsynaptic shank antagonizes dendrite branching induced by the leucine-rich repeat protein Densin-180, J. Neurosci. 25 (2) (2005) 479-487.

[152] Y. Zhang, S. Yeh, B.A. Appleton, H.A. Held, P.J. Kausalya, D.C. Phua, W.L. Wong, L.A. Lasky, C. Wiesmann, W. Hunziker, S.S. Sidhu, Convergent and divergent ligand specificity among PDZ domains of the LAP and zonula occludens (ZO) families, J. Biol. Chem. 281 (31) (2006) 22299-22311.

[153] H.J. Carlisle, T.N. Luong, A. Medina-Marino, L. Schenker, E. Khorosheva, T. Indersmitten, K.M. Gunapala, A.D. Steele, T.J. O'Dell, P.H. Patterson, M.B. Kennedy, Deletion of densin-180 results in abnormal behaviors associated with mental illness and reduces mGluR5 and DISC1 in the postsynaptic density fraction, J. Neurosci. 31 (45) (2011) 16194-16207.

[154] K. Shen, T. Meyer, Dynamic control of CaMKII translocation and localization in hippocampal neurons by NMDA receptor stimulation, Science 284 (5411) (1999) $162-166$.

[155] K. Shen, M.N. Teruel, J.H. Connor, S. Shenolikar, T. Meyer, Molecular memory by reversible translocation of calcium/calmodulin-dependent protein kinase II, Nat. Neurosci. 3 (9) (2000) 881-886.

[156] A.J. Baucum 2nd, B.C. Shonesy, K.L. Rose, R.J. Colbran, Quantitative proteomics analysis of CaMKII phosphorylation and the CaMKII interactome in the mouse forebrain, ACS Chem. Neurosci. 6 (4) (2015) 615-631.

[157] F. Gardoni, A. Caputi, M. Cimino, L. Pastorino, F. Cattabeni, M. Di Luca, Calcium/ calmodulin-dependent protein kinase II is associated with NR2A/B subunits of NMDA receptor in postsynaptic densities, J. Neurochem. 71 (4) (1998) 1733-1741.

[158] Y. Zhou, E. Takahashi, W. Li, A. Halt, B. Wiltgen, D. Ehninger, G.D. Li, J.W. Hell, M.B. Kennedy, A.J. Silva, Interactions between the NR2B receptor and CaMKII modulate synaptic plasticity and spatial learning, J. Neurosci. 27 (50) (2007) $13843-13853$.

[159] A.R. Halt, R.F. Dallapiazza, Y. Zhou, I.S. Stein, H. Qian, S. Juntti, S. Wojcik, N. Brose, A.J. Silva, J.W. Hell, CaMKII binding to GluN2B is critical during memory consolidation, EMBO J. 31 (5) (2012) 1203-1216.

[160] J. Tsui, M. Inagaki, H. Schulman, Calcium/calmodulin-dependent protein kinase II (CaMKII) localization acts in concert with substrate targeting to create spatial restriction for phosphorylation, J. Biol. Chem. 280 (10) (2005) 9210-9216.

[161] H.E. Lu, H.D. MacGillavry, N.A. Frost, T.A. Blanpied, Multiple spatial and kinetic subpopulations of CaMKII in spines and dendrites as resolved by single-molecule tracking PALM, J. Neurosci. 34 (22) (2014) 7600-7610.

[162] L.A. Cingolani, Y. Goda, Actin in action: the interplay between the actin cytoskeleton and synaptic efficacy, Nat. Rev. Neurosci. 9 (5) (2008) 344-356.

[163] A. Fera, A. Dosemeci, A.A. Sousa, C. Yang, R.D. Leapman, T.S. Reese, Direct visualization of CaMKII at postsynaptic densities by electron microscopy tomography, J. Comp. Neurol. 520 (18) (2012) 4218-4225.

[164] R. Walker-Gray, F. Stengel, M.G. Gold, Mechanisms for restraining cAMP-dependent protein kinase revealed by subunit quantitation and cross-linking approaches, Proc. Natl. Acad. Sci. U. S. A. 114 (39) (2017) 10414-10419.

[165] S. Chen, Y. Zhao, Y. Wang, M. Shekhar, E. Tajkhorshid, E. Gouaux, Activation and desensitization mechanism of AMPA receptor-TARP complex by Cryo-EM, Cell 170 (6) (2017) 1234-1246 (e14.

[166] L.C. Reese, G. Taglialatela, A role for calcineurin in Alzheimer's disease, Curr. Neuropharmacol. 9 (4) (2011) 685-692.

[167] A. Ghosh, K.P. Giese, Calcium/calmodulin-dependent kinase II and Alzheimer's disease, Mol. Brain 8 (1) (2015) 78.

[168] A.J. Robison, Emerging role of CaMKII in neuropsychiatric disease, Trends Neurosci. 37 (11) (2014) 653-662.

[169] E. Mick, J. McGough, S. Loo, A.E. Doyle, J. Wozniak, T.E. Wilens, S. Smalley, J. McCracken, J. Biederman, S.V. Faraone, Genome-wide association study of the child behavior checklist dysregulation profile, J. Am. Acad. Child Adolesc. Psychiatry 50 (8) (2011) 807-17 e8). 